\title{
An inhibitor of transforming growth factor beta type I receptor ameliorates muscle atrophy in a mouse model of caveolin 3-deficient muscular dystrophy
}

\author{
Yutaka Ohsawa', Tadashi Okada', Shin-ichiro Nishimatsu², Masatoshi Ishizaki ${ }^{3}$, Tomohiro Suga ${ }^{3}$, \\ Masahiro Fujino ${ }^{1}$, Tatsufumi Murakami ${ }^{1}$, Makoto Uchino ${ }^{3}$, Kunihiro Tsuchida ${ }^{4}$, Sumihare Noji ${ }^{5}$, \\ Atsushi Hinohara ${ }^{6}$, Toshiyuki Shimizu ${ }^{7}$, Kiyoshi Shimizu ${ }^{6}$ and Yoshihide Sunada ${ }^{1}$
}

Skeletal muscle expressing Pro104Leu mutant caveolin 3 (CAV3 ${ }^{\text {P104L }}$ ) in mouse becomes atrophied and serves as a model of autosomal dominant limb-girdle muscular dystrophy 1C. We previously found that caveolin 3-deficient muscles showed activated intramuscular transforming growth factor beta (TGF- $\beta$ ) signals. However, the cellular mechanism by which loss of caveolin 3 leads to muscle atrophy is unknown. Recently, several small-molecule inhibitors of TGF- $\beta$ type I receptor (T $\beta \mathrm{RI})$ kinase have been developed as molecular-targeting drugs for cancer therapy by suppressing intracellular TGF- $\beta 1,-\beta 2$, and $-\beta 3$ signaling. Here, we show that a T $\beta$ RI kinase inhibitor, Ki26894, restores impaired myoblast differentiation in vitro caused by activin, myostatin, and TGF- $\beta 1$, as well as CAV3 ${ }^{\mathrm{P} 104 \mathrm{~L}}$. Oral administration of Ki26894 increased muscle mass and strength in vivo in wild-type mice, and improved muscle atrophy and weakness in the CAV3 ${ }^{\mathrm{P} 104 \mathrm{~L}}$ mice. The inhibitor restored the number of satellite cells, the resident stem cells of adult skeletal muscle, with suppression of the increased phosphorylation of Smad2, an effector, and the upregulation of $p 21$ (also known as Cdkn1a), a target gene of the TGF- $\beta$ family members in muscle. These data indicate that both TGF- $\beta$-dependent reduction in satellite cells and impairment of myoblast differentiation contribute to the cellular mechanism underlying caveolin 3-deficient muscle atrophy. T $\beta$ RI kinase inhibitors could antagonize the activation of intramuscular anti-myogenic TGF- $\beta$ signals, thereby providing a novel therapeutic rationale for the alternative use of this type of anticancer drug in reversing muscle atrophy in various clinical settings.

Laboratory Investigation (2012) 92, 1100-1114; doi:10.1038/labinvest.2012.78; published online 14 May 2012

KEYWORDS: caveolin 3; limb-girdle muscular dystrophy 1C; muscular atrophy; myoblast; satellite cell; small-molecule kinase inhibitor; transforming growth factor- $\beta$ type I receptor kinase

Muscle atrophy impairs the activities of daily living and is implicated in fatal outcomes in various diseases, including muscular dystrophy and cancer. ${ }^{1,2}$ Recently, a growing number of transcription factors, membrane and cytoskeletal proteins, and cytokines have been found to participate in the molecular mechanisms leading to muscle atrophy, including caveolin 3 and myostatin. ${ }^{3-8}$

Caveolin 3, a muscle-specific integral membrane protein, forms flask-shaped invaginations of the plasma membrane known as caveolae, and regulates signal transduction pathways by binding specific lipid-modified signal molecules, including Ha-Ras, G protein-coupled receptors, Srk-family kinases, and nitric oxide synthases. ${ }^{9}$ Loss of caveolin 3 resulting from dominant-negative mutations in the CAV3 gene causes autosomal dominant limb-girdle muscular dystrophy (LGMD) 1C., ${ }^{9,10}$ We previously developed a transgenic mouse overexpressing Pro104Leu mutant caveolin $3\left(\mathrm{CAV}^{\mathrm{P} 104 \mathrm{~L}}\right)$ as a model of LGMD1C; these mice demonstrated myopathy characterized by muscle atrophy. ${ }^{11}$ We found that the caveolin 3-deficient muscles in the transgenic mice showed activation

\footnotetext{
${ }^{1}$ Department of Neurology, Kawasaki Medical School, Okayama, Japan; ${ }^{2}$ Department of Molecular and Developmental Biology, Kawasaki Medical School, Okayama, Japan; ${ }^{3}$ Department of Neurology, Kumamoto University Graduate School of Medical Sciences, Kumamoto, Japan; ${ }^{4}$ Division for Therapies against Intractable Diseases, Institute for Comprehensive Medical Science, Fujita Health University, Aichi, Japan; ${ }^{5}$ Department of Life Systems, Institute of Technology and Science, The University of Tokushima Graduate School, Tokushima, Japan; ${ }^{6}$ Drug Discovery Research Laboratories, Research Division, Kyowa Hakko Kirin, Shizuoka, Japan and ${ }^{7}$ Research Planning Department, Research Division, Kyowa Hakko Kirin, Tokyo, Japan

Correspondence: Professor Y Sunada, MD, PhD, Department of Neurology, Kawasaki Medical School, 577 Matsushima, Kurashiki, Okayama 701-0192, Japan.

E-mail: ysunada@med.kawasaki-m.ac.jp

Received 30 August 2011; revised 23 February 2012; accepted 27 February 2012
} 
of intramuscular transforming growth factor beta (TGF- $\beta$ )mediated signals, including myostatin, which is specifically expressed in skeletal muscle and negatively regulates muscle mass and growth. ${ }^{5-8}$ However, the cellular pathobiology leading to muscle atrophy caused by the loss of caveolin 3 and activated intramuscular TGF- $\beta$ signals remains to be elucidated.

Small-molecule compounds to antagonize TGF- $\beta$ signals at membrane receptor serine/threonine kinases have recently been proposed as molecular-targeted drugs for cancer therapy. ${ }^{12}$ Tumor cells in advanced stages become refractory to TGF- $\beta$-induced growth arrest, but often overexpress TGF- $\beta 1$, $-\beta 2$, and $-\beta 3 .{ }^{13}$ TGF- $\beta$ family members induce the epithelialmesenchymal transition, immunosuppression, and angiogenesis, resulting in tumor growth and metastasis. Each member of the TGF- $\beta$ family binds to a membrane serine/ threonine kinase receptor, termed as a type II receptor, which then recruits a type I kinase receptor. ${ }^{1,14}$ Seven different type I receptors, the activin receptor-like kinases 1-7 (ALK1-7), thus determine the intracellular signal specificity of the 33 members of the TGF- $\beta$ family. ${ }^{1,14}$ Small-molecule inhibitors of TGF- $\beta$ type I receptor (T $\beta$ RI) kinase were originally developed to compete with the binding of adenosine triphosphate to the kinase domain of ALK5, the type I receptor for TGF- $\beta 1-3 .{ }^{12} \mathrm{~T} \beta$ RI kinase inhibitors have been found to suppress tumor enlargement and metastasis in the advanced stages of cancer in animals. ${ }^{15-18}$ Notably, these inhibitors also suppress a similar kinase domain of ALK4, the type I receptor for activin, and potentially block ALK4/5, the type I receptor for myostatin. ${ }^{1,12,19,20}$ However, the impact and clinical significance of T $\beta$ RI kinase inhibitors on the skeletal muscle signaling of activin, myostatin, and TGF- $\beta 1-3$ is unknown.

Considering the potential broad suppression profile of $\mathrm{T} \beta \mathrm{RI}$ kinase inhibitors on the multiple intramuscular TGF- $\beta$ signals, we postulated that these inhibitors could be used as optimal probes to explore the cellular mechanisms of how activated intramuscular TGF- $\beta$ signals lead to muscle atrophy in caveolin 3-deficient muscular dystrophy. Alternatively, by suppressing the multiple anti-myogenic TGF- $\beta$ signals, pharmacological intervention using this type of inhibitor would be expected to prevent muscle atrophy in caveolin 3deficient mice. In the current study, we tested our hypothesis by examining the effects of T $\beta$ RI kinase inhibitors on myogenesis via muscle precursor satellite cells, as well as myoblasts. The ability of an oral inhibitor to increase muscle mass, or to slow the progression of atrophy and weakness was further investigated in wild-type or caveolin 3-deficient mice, to investigate its potential in the future treatment of patients with muscular atrophy.

\section{MATERIALS AND METHODS Cell Lines and Reagents}

A204 human rhabdomyosarcoma cells, HEK293 human embryonic kidney cells, and HaCaT human keratinocytes were maintained in Dulbecco's modified Eagle's medium
(DMEM) containing 10\% fetal bovine serum (FBS), $2 \mathrm{mM}$ L-glutamine, $0.1 \mathrm{mM}$ non-essential amino acids, and $50 \mu \mathrm{g} / \mathrm{ml}$ kanamycin. The pGL3-(CAGA) 12 -luciferase reporter containing the TGF- $\beta$-sensitive Smad-binding sequence (CAGA) was kindly provided by Dr C-H Heldin (Uppsala University, Sweden). ${ }^{21}$ Recombinant myostatin, activin A, and TGF- $\beta 1$ (R\&D Systems, Minneapolis, MN, USA) were prepared as $100 \mu \mathrm{g} / \mathrm{ml}$ stock solutions in $0.1 \%$ bovine serum albumin with $4 \mathrm{mM} \mathrm{HCl}$. The small-molecule T $\beta$ RI kinase inhibitors, Ki26894 (FW 374.40; Kyowa Hakko Kirin, Nagaizumi, Shizuoka, Japan), SB-431542 (FW 420.42; Sigma-Aldrich, St Louis, MO, USA), and LY-364947 (FW 327.30; Chemicon, Temecula, CA, USA) were dissolved and serially diluted from $10 \mathrm{mM}$ to $1 \mu \mathrm{M}$ in dimethyl sulfoxide as 1000 -fold concentrated solutions. $\mathrm{C} 2 \mathrm{C} 12$ myoblasts were maintained in growth medium comprising DMEM plus 10\% FBS. The pMXs-IRES-GFP retroviral vector and the Plat-E packaging cells, and the antibody raised against $\mathrm{M}$-cadherin, also known as cadherin 15 (CDH15), for satellite cell analysis, were kind gifts from $\mathrm{T}$ Kitamura (Institute of Medical Science, The University of Tokyo, Japan), and Drs Y Miyagoe-Suzuki and S-I Takeda (National Institute of Neuroscience, National Center of Neurology and Psychiatry, Japan), respectively.

\section{Luciferase Assays}

A204 cells or HEK293 cells were seeded on 12-well plates at $1.0 \times 10^{5}$ cells/well and maintained for $24 \mathrm{~h}$, respectively. These cells were then co-transfected with the pGL3(CAGA) ${ }_{12}$-luciferase reporter gene. After $24 \mathrm{~h}$, the medium was replaced with DMEM containing $10 \mathrm{ng} / \mathrm{ml}$ recombinant myostatin, $10 \mathrm{ng} / \mathrm{ml}$ activin A, or $6 \mathrm{ng} / \mathrm{ml}$ TGF- $\beta 1$. The T $\beta$ RI kinase inhibitors, Ki26894, SB-431542, or LY-364947 were also added to the culture medium. After an additional $24 \mathrm{~h}$, cells were lysed with $1 \times$ lysis buffer (Promega, Madison, WI, USA) and luciferase activity in the cell lysates was determined by a luciferase reporter assay system (Promega) using a MiniLumat LB 9506 luminometer (EG\&G Berthold, Nashua, $\mathrm{NH}, \mathrm{USA}$ ) and was normalized to $\beta$-galactosidase activity. For the ex-vivo myostatin bioassay, sera from mice fed without or with Ki26894 were diluted four-fold (to 25\%) with DMEM containing $10 \mathrm{ng} / \mathrm{ml}$ recombinant myostatin. The resulting mixture was added to HEK293 cells co-transfected with the pGL3-(CAGA) 12 -luciferase reporter gene and pCMV- $\beta$-Gal.

\section{In-Vitro Expression Assay for $p 21$ and p15}

HaCaT human keratinocyte cells were seeded in 10-cm dishes at $1.0 \times 10^{6}$ cells/dish and maintained for $24 \mathrm{~h}$, followed by incubation in serum-free medium for $2 \mathrm{~h}$. The cells were then incubated with or without Ki26894 plus $10 \mathrm{ng} / \mathrm{ml}$ recombinant myostatin, $10 \mathrm{ng} / \mathrm{ml}$ activin $\mathrm{A}$, or $6 \mathrm{ng} / \mathrm{ml}$ TGF- $\beta 1$. Cellular RNA was extracted at the indicated times and the gene expression of $p 21$, also known as cyclin-dependent kinase inhibitor (Cdkn) $1 a$, and p15, also known as $C d k n 1 b$, was examined by northern blotting. 


\section{Construction of Retroviral Vectors}

Mouse cDNAs for myostatin, activin A, and TGF- $\beta 1$ were cloned into retroviral vectors. The NcoI-Sali fragment of green fluorescent protein (GFP) cDNA in the original pMXsIRES-GFP retroviral vector ${ }^{22}$ was substituted with the Cherry cDNA fragment derived from the pmCherry-N1 plasmid vector (Clontech, Mountain View, CA, USA). One microgram of total RNA from mouse skeletal muscle was reverse transcribed with an oligo $(\mathrm{dT})_{12-18}$ primer and subjected to PCR using the following primers: myostatin, 5'-CGGGATCCATGATGCAAAAACTG- $3^{\prime}$ and $5^{\prime}$-CGGAATTCTCATGAGCACCCAC- $3^{\prime}$; activin A, 5'-CGGAATTCATGCCCTTGCTT TGG-3' and 5'-CGCTCGAGCTAGGAGCAGCCAC-3'; TGF- $\beta 1,5^{\prime}$-CGGAATTCATGCCGCCCTCGGGG- $3^{\prime}$ and $5^{\prime}-$ CGCTCGAGTCAGCTGCACTTGC- $3^{\prime}$. The resulting PCR products were then cloned into the pMXs-IRES-Cherry vector using the appropriate restriction sites. The cDNA fragments of the Pro104Leu mutant caveolin 3 (ref. 5) were also ligated to the original vector.

\section{In-Vitro Myogenic Differentiation Assays}

Using the above retroviral vectors, we generated $\mathrm{C} 2 \mathrm{C} 12$ cells expressing TGF- $\beta$ family members, or Pro104Leu mutant caveolin 3 , according to a method previously described. ${ }^{22}$ Briefly, C2C12 myoblasts were maintained in growth medium comprising DMEM plus 10\% FBS. Myogenic differentiation was initiated by placing $60 \%$ confluent cultures in differentiation medium comprising DMEM plus 2\% horse serum with or without $10 \mathrm{nM}$ Ki26894. Retrovirus vectors expressing TGF- $\beta$ family members or mutant caveolin 3 were then transfected into Plat-E packaging cells. Supernatants containing retrovirus were passed through $0.45 \mu \mathrm{m}$ filters. $\mathrm{C} 2 \mathrm{C} 12$ cells were infected with the filtrates for $6 \mathrm{~h}$ and the medium was then replaced with differentiation medium. For immunocytochemical analysis, the cells were fixed and stained with anti-myosin heavy chain $(\mathrm{MyHC})$ monoclonal antibody (mAb) (MY-32; Sigma-Aldrich), anti-muscle creatine kinase-M polyclonal antibody (N-13; Santa Cruz Biotechnology, Santa Cruz, CA, USA), or anti-myogenin mAb (F5D; Santa Cruz Biotechnology), followed by Alexa 488-conjugated anti-mouse or anti-goat IgG antibody (Invitrogen, Carlsbad, CA, USA). Lysates from C2C12 cells were resolved by SDS-polyacrylamide gel electrophoresis and transferred onto a polyvinylidene fluoride membrane. Immunoblot analysis was performed using MY-32.

\section{Fusion Indices}

The number of nuclei in mononucleated cells and myotubes defined as syncytia containing $>3$ nuclei were counted in four independent fields of $1 \mathrm{~mm}^{2}(n=5)$. The fusion indices were calculated as ratios (\%) of the total number of nuclei incorporated in myotubes.

\section{Animals and Administration of Ki26894}

Transgenic mice overexpressing the LGMD1C-causing Pro104Leu mutant caveolin $3\left(\mathrm{CAV} 3^{\mathrm{P} 104 \mathrm{~L}}\right)^{9}$ under the control of $6.5 \mathrm{~kb}$ of the muscle creatinine kinase $(M C K)$ gene promoter/enhancer sequences, including $3.3 \mathrm{~kb}$ upstream of exon 1 , the complete intron 1 and exon 2 truncated just $5^{\prime}$ of the initiator methionine, were generated previously. ${ }^{11}$ These mice demonstrated myopathy characterized by muscle atrophy and loss of caveolin-3, with increased intramuscular TGF- $\beta$ signal. ${ }^{5,6,11}$ Ki26894 was mixed with normal powdered food (CE-2; CLEA, Hamamatsu, Shizuoka, Japan) to a final concentration of $0.08 \%$, and was orally administered to caveolin 3-deficient transgenic mice $\left(\mathrm{CAV} 3^{\mathrm{P} 104 \mathrm{~L}}\right)$ or control wild-type mice aged between 6 and 16 weeks, as described. ${ }^{18}$ All animal experiments were performed at the Laboratory Animal Center and were approved by the Animal Research Committee of Kawasaki Medical School.

\section{Immunohistochemical and Morphometric Analyses}

Frozen quadriceps femoris muscles were transversely sectioned at the center of the muscles. The sections were fixed and stained using the anti-rat laminin $\alpha 2 \mathrm{mAb}$ (4H8-2; Sigma-Aldrich) followed by Alexa 488-conjugated anti-rat IgG antibody (Invitrogen). The areas of single myofibers in the quadriceps muscles $(n=20 ; 250$ myofibers per mouse) were measured on fluorescence images of laminin $\alpha 2$-stained sections using the two-color technique, as previously described..$^{5}$ To detect infiltration of inflammatory cells in muscles, sections were stained with a rat anti-mouse CD11b mAb (BD Pharmingen, San Diego, CA, USA).

For satellite cell analysis, the sections were stained with an anti-rabbit M-cadherin polyclonal antibody raised against the carboxyl-terminal region of mouse M-cadherin (Invitrogen) and an anti-rat laminin $\alpha 2 \mathrm{mAb} 4 \mathrm{H} 8-2$ (Sigma-Aldrich) followed by Alexa 488-conjugated antirabbit IgG and Alexa 594-conjugated anti-rat IgG Abs (Invitrogen). Myonuclei were post-stained with 4',6-diamidino-2-phenylindole, DAPI (Vector Laboratories, Burlingame, CA, USA). The findings were confirmed using another anti-rabbit M-cadherin polyclonal antibody raised against amino acids 399-444 of mouse M-cadherin, as shown in Supplementary Figure 7.

\section{Isolation of Single Myofiber and Attached Satellite Cells} We isolated single myofibers from the extensor digitorum longus (EDL) muscles of mice aged 16 weeks according to a previously described method. ${ }^{23}$ Briefly, EDL muscles were digested in freshly prepared $0.5 \%$ type I collagenase (Worthington Laboratories, Freehold, NJ, USA) in DMEM. After gentle sucking of these muscle digests in and out of a widebore flame-polished Pasteur pipette, a single myofiber was isolated and placed individually on a coverslip precoated with $1 \mathrm{mg} / \mathrm{ml}$ Matrigel (BD Bioscience, San Jose, CA, USA). The single myofiber was fixed with $4 \%$ paraformaldehyde in PBS and stained with a rabbit anti-mouse caveolin-1 pAb 
(BD Transduction Laboratories, Lexington, KY, USA), an anti-mouse caveolin-3 mAb (Santa Cruz), and an anti-mouse Pax7 mAb (GT), followed by labeling with Alexa 488conjugated anti-rabbit and Alexa Fluor 594-conjugated anti-mouse IgG antibodies (Molecular Probe). Nuclei were post-stained with DAPI. Immunofluorescence images were captured using a laser scanning confocal microscope (TCS SP2; Leica Microsystems, Wetzlar, Germany) or a fully motorized inverse microscope (IX81, Olympus, Tokyo, Japan).

\section{Vital Staining of Damaged Myofibers}

To detect damaged myofibers, Evans Blue dye (EBD, $20 \mathrm{mg} /$ $\mathrm{ml}$ in PBS) was injected into mice $(0.15 \mathrm{ml} / 10 \mathrm{~g}$ body weight $)$ intraperitoneally, basically according to a previously described method. ${ }^{24}$ Mice were killed $24 \mathrm{~h}$ after injections. Skeletal muscles were sectioned and fluorescence images were evaluated under a fully motorized inverse microscope.

\section{Muscle Performance}

Mice grasping a wire mesh with their limbs were pulled horizontally by their tail until they lost their grip. Peak grip strength (g) was measured using an MK-380S automated Grip Strength Meter (Muromachi, Tokyo, Japan). The tetanic force of the tibialis anterior (TA) or diaphragm of mice at 16 weeks of age was measured essentially as previously described. ${ }^{25}$ Briefly, the TA or diaphragm was quickly excised and the peripheral tendons were secured with a 5-0 silk suture. Both ends of the muscle were fixed using a tissue clamp (B-small; Natsume, Tokyo, Japan). The muscle was vertically mounted in a chamber that was perfused with oxygen-saturated Ringer's solution and maintained at $25^{\circ} \mathrm{C}$. The muscle was then connected to a UL-50GR force transducer (Minebea), and an MM-3 length servosystem (Narishige, Tokyo, Japan). The muscle was stimulated through a pair of platinum plates attached at both sides of the chamber using an SEN-3401 electronic stimulator (Nihon Kohden, Tokyo, Japan). Tetanic force was recorded and analyzed using a PowerLab system and LabChart v6 software (ADInstruments, Colorado Springs, CO, USA). The length of the muscle fibers was incrementally adjusted using a micropositioner until the maximal twitch force response was obtained (optimal fiber length). The maximal tetanic force was assessed at a stimulation frequency of $150 \mathrm{~Hz}$ delivered in $1000 \mathrm{~ms}$ trains with $2 \mathrm{~min}$ intervals between trains. After obtaining three measurements, the attached bone and sutures were removed and the muscle was weighed. The muscle crosssectional area was calculated using the formula: muscle wet weight (in $\mathrm{mg}$ )/optimal fiber length (in $\mathrm{mm}$ ) $\times 1.056$ (in $\mathrm{mg} / \mathrm{mm}^{3}$ ). Specific tetanic forces (maximal tetanic force/ cross-sectional area) of the muscle were determined using the estimated cross-sectional area.

\section{RT-PCR and Northern Blotting}

Total RNAs from mouse skeletal muscle or HaCaT cells were fractionated on northern gels, and probed with labeled
cDNAs for mouse p21 (nucleotides (nt) 1-255), mouse p15 (nt 32-385), mouse 18S rRNA (nt 1-453), human p21 (nt 1-255), or human p15 (nt 508-921).

\section{Smad2 Phosphorylation Analysis}

Skeletal muscle from 16-week-old mice was homogenized in 10 volumes (w/v) of a buffer consisting of $50 \mathrm{mM}$ Tris- $\mathrm{HCl}$ $(\mathrm{pH}$ 7.4) $, 100 \mathrm{mM} \mathrm{NaCl}, 1 \mathrm{mM}$ EDTA, $5 \mathrm{mM} \beta$-mercaptoethanol, $0.1 \mathrm{mM}$ PMSF, and $1 \mathrm{mM}$ benzamidine. The crude extracts were resolved by SDS-polyacrylamide gel electrophoresis and transferred onto polyvinylidene fluoride membranes. Immunoblot analysis was performed using rabbit anti-mouse Smad2 or phosphorylated Smad2 (p-Smad2) (Ser465/467) antibodies (Cell Signaling Technology, Danvers, MA, USA).

\section{Statistics}

Paired observations were statistically analyzed using one-way analysis of variance followed by Bonferroni's test. $P$-values $<0.05$ were considered statistically significant.

\section{RESULTS}

T $\beta$ RI Kinase Inhibitors Broadly Suppress the In-Vitro Transcriptional Activities of TGF- $\beta$ Family Members

To investigate whether T $\beta$ RI kinase inhibitors can suppress TGF- $\beta$ signals other than TGF- $\beta 1-3$ in vitro, we tested three inhibitors: SB-431542, LY-364947, and Ki26894. ${ }^{17-20}$ A204 human rhabdomyosarcoma cells or HEK293 human embryonic kidney cells were transfected with pGL3-(CAGA) ${ }_{12}{ }^{-}$ luciferase, a TGF- $\beta$-sensitive Smad-responsive luciferase reporter gene. ${ }^{21}$ Stimulation of these cells with recombinant myostatin, activin A, or TGF- $\beta 1$ caused a significant increase in luciferase activity above the basal level (A204: Figure 1a-c; HEK293: Figure 1d-f). The addition of an individual inhibitor to the culture media suppressed luciferase activity in a dosedependent manner. The intracellular signal specificity of myostatin, activin A, or TGF- $\beta 1$ is determined by the recruitment of ALK4/5. ${ }^{1}$ Thus, these T $\beta$ RI kinase inhibitors can suppress the intracellular signaling of myostatin through ALK4/5, activin A through ALK4, and TGF- $\beta 1$ through ALK5. In A204 cells, the three inhibitors suppressed myostatin, activin A, or TGF- $\beta 1$ comparably, whereas in HEK293 cells, Ki26894 inhibited myostatin $\sim 15$-fold more potently than either SB-431542 or LY-364947 with half-maximal inhibitory concentration values of 7,100 , and $100 \mathrm{nM}$, respectively. We selected Ki26894 as a representative inhibitor for subsequent experiments.

We further investigated the effects of Ki26894 on TGF- $\beta$ induced gene expression of the cyclin-dependent kinase (CDK) inhibitors, $p 21$ and $p 15$ in HaCaT human keratinocyte cells, a cell line in which the intracellular signaling pathways activated by different members of the TGF- $\beta$ family have been characterized in detail. ${ }^{26}$ Myostatin time dependently induced the expression of $p 21$, but not of $p 15$, while Ki26894 suppressed p21 upregulation (Figure 1d). Ki26894 
also blocked p21 expression induced by activin A and TGF$\beta 1$. Thus, this T $\beta$ RI kinase inhibitor suppressed the common intracellular signal pathways leading to $p 21$ upregulation that are induced by the different members of the TGF- $\beta$ family.
Ki26894 Reverses Impaired Myoblast Differentiation In Vitro Caused by TGF- $\beta 1$, Activin, and Myostatin Myostatin suppresses the differentiation of $\mathrm{C} 2 \mathrm{C} 12$ myoblasts exposed to low-serum conditions. ${ }^{27}$ Using an efficient a

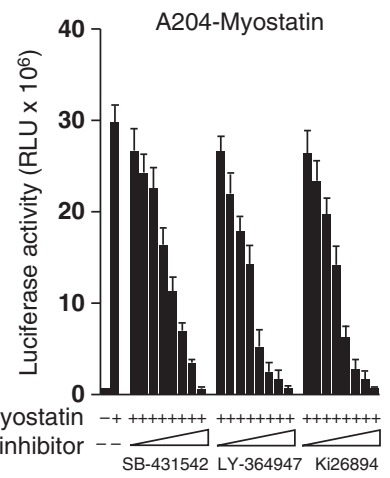

b

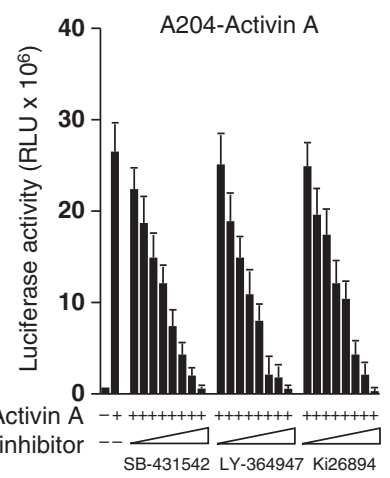

C

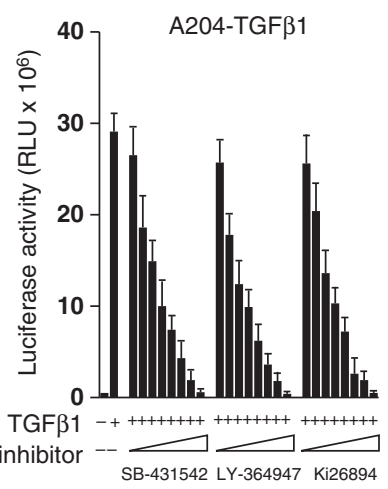

d

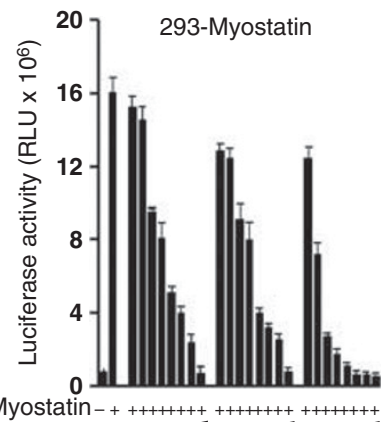

TRRI kinase inhibitor -- $\overbrace{\text { SB-431542 }}^{\text {LY-364947 Ki26894 }}$

e

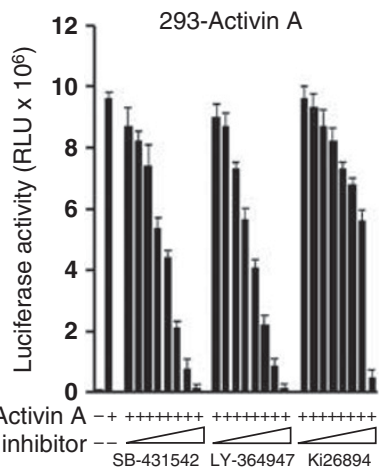

$\mathbf{f}$

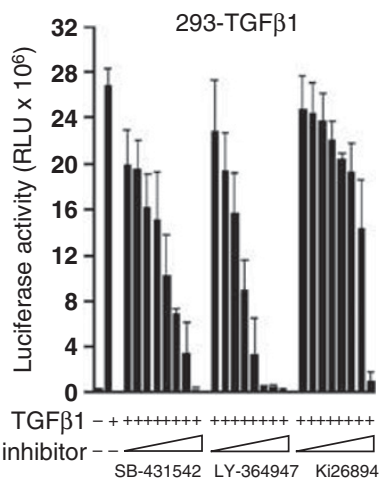

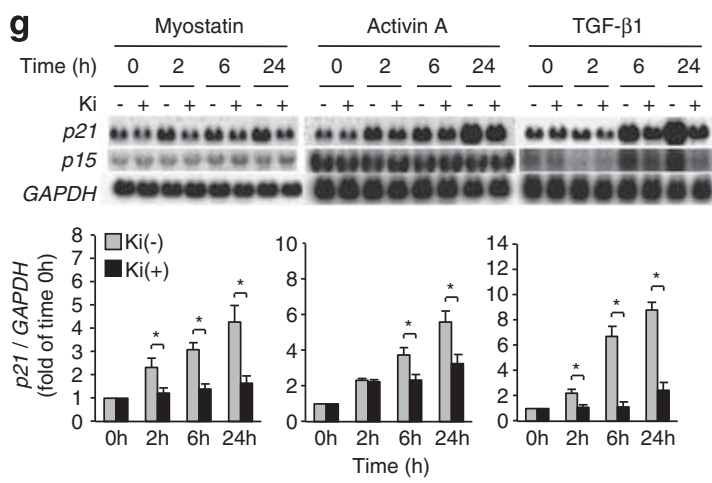


retrovirus-mediated gene transfer system, ${ }^{22}$ we assessed the effect of Ki26894 on the differentiation of C2C12 myoblasts expressing TGF- $\beta 1$ or activin A, as well as myostatin. Trans- ferring $\mathrm{C} 2 \mathrm{C} 12$ myoblasts expressing an empty vector from high-serum (growth) to low-serum (differentiation) media caused them to fuse and form multinucleated myotubes. We a

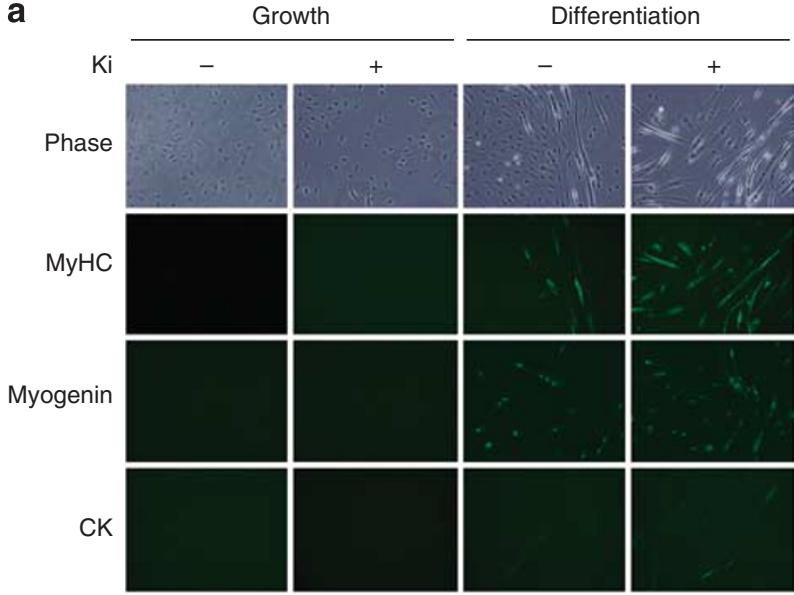

b

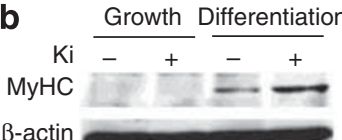

C

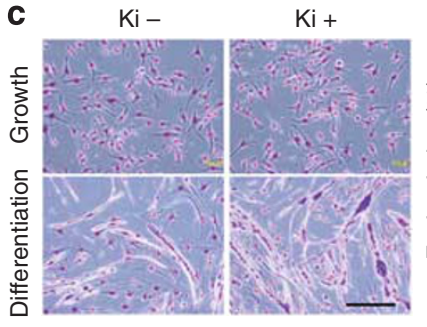

d

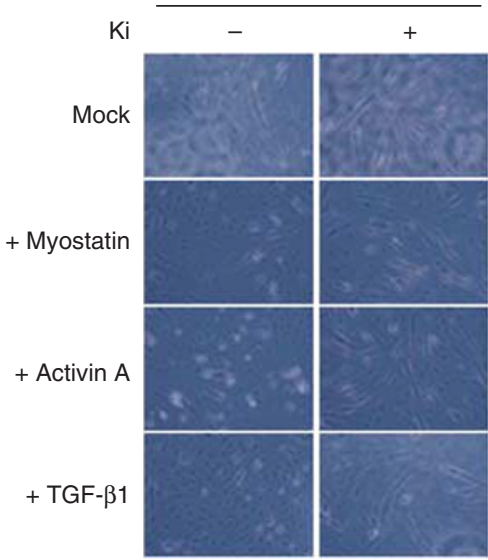

MyHC

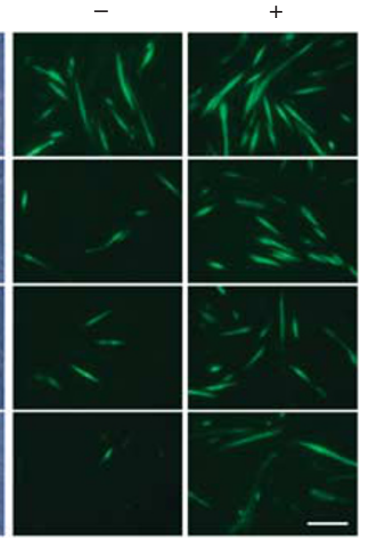

e
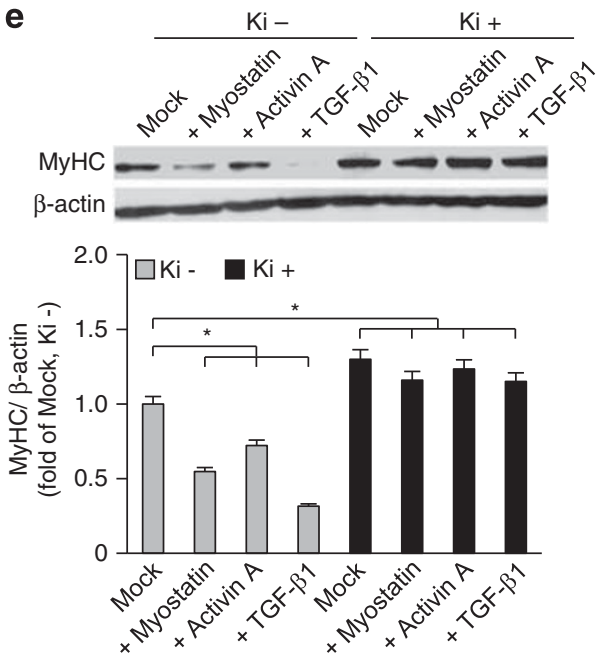

Figure 2 The T $\beta$ RI kinase inhibitor Ki26894 (Ki) reverses the impaired in-vitro myogenesis caused by myostatin, activin A, and TGF- $\beta 1$. (a) C2C12 myoblasts expressing an empty vector were grown in DMEM containing $10 \%$ FBS (growth medium) and then differentiated in DMEM containing $2 \%$ horse serum

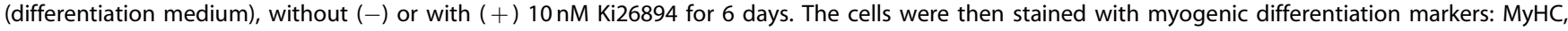
myogenin, or CK. Phase-contrast and fluorescent images. Bar, $5 \mu \mathrm{m}$. (b) Immunoblot analysis of MyHC in lysates from C2C12 cells expressing an empty vector in growth medium or differentiation medium without $(-)$ or with (+) Ki26894. (c) Giemsa and Wright-stained images of C2C12 cells expressing an empty vector in growth medium or differentiation medium without $(-)$ or with $(+)$ Ki26894 (left). Fusion indices of these cells following the addition of $10 \mathrm{nM} \mathrm{Ki26894}$ were calculated in triplicate as the percent of the total nuclei in myotubes $/ \mathrm{mm}^{2}$ (right). Values are means $\pm \mathrm{s} . \mathrm{d}$. $(n=5)$. ${ }^{\star} P<0.05$. (d) $\mathrm{C} 2 \mathrm{C} 12$ myoblasts expressing empty vector (mock), myostatin, activin A, or TGF- $\beta 1$ were cultured in differentiation medium without $(-)$ or with (+) $10 \mathrm{nM} \mathrm{Ki26894}$ for 6 days and then stained with MyHC. Phase-contrast (left) and fluorescent (right) images are shown. Bar, $15 \mu \mathrm{m}$. (e) Analysis of MyHC protein expression in lysates from C2C12 cells expressing empty vector (mock), myostatin, activin A, or TGF- $\beta 1$ at 6 days after differentiation without (-) or with (+) Ki26894 (upper). Densitometric analysis of the $\mathrm{MyHC} / \beta$-actin ratio in differentiated $\mathrm{C} 2 \mathrm{C} 12$ cells (lower). Values are mean \pm s.d. fold increases compared with untreated $\mathrm{C} 2 \mathrm{C} 12$ lysates expressing empty vector (mock) $(n=5) .{ }^{*} P<0.05$.

Figure 1 T $\beta$ RI kinase inhibitors suppress myostatin-, activin A-, and TGF- $\beta 1$-induced transcriptional activities in vitro. A204 human rhabdomyosarcoma cells (left; a-c) or HEK293 human embryonic kidney cells (right; $\mathbf{d}-\mathbf{f}$ ) were co-transfected with both the Smad-responsive luciferase reporter gene pGL3-(CAGA) $12^{-}$ luciferase and pCMV- $\beta$-Gal. Cells were stimulated $24 \mathrm{~h}$ later with $10 \mathrm{ng} / \mathrm{ml}$ of myostatin $(\mathbf{a}, \mathbf{d}), 10 \mathrm{ng} / \mathrm{ml}$ of activin A (b, e), or $6 \mathrm{ng} / \mathrm{ml}$ of TGF- $\beta 1(\mathbf{c}, \mathbf{f})$ and simultaneously exposed to increasing concentrations $(1,10,50,100,250,500,1000$, or $10000 \mathrm{nM}$; indicated by triangles) of SB-431542 (left), LY-364947 (center), or Ki26894 (right). Luciferase activity was measured and normalized to $\beta$-Gal activity. Values are means \pm s.d. $(n=10)$. RLU, relative luminescence units. (g) $\mathrm{HaCaT}$ human keratinocytes were cultured in medium containing serum. After preincubation in serum-free medium for $2 \mathrm{~h}$, the cells were stimulated with $10 \mathrm{ng} / \mathrm{ml}$ recombinant myostatin (left), $10 \mathrm{ng} / \mathrm{ml}$ activin A (center), or $6 \mathrm{ng} / \mathrm{ml} \mathrm{TGF-} \beta 1$ (right) (upper). Cells were then maintained without (-) or with (+) $10 \mathrm{nM} \mathrm{Ki26894}$ (Ki). The gene expression levels of $p 21$ or $p 15$ in cells at $0,2,6$, and $24 \mathrm{~h}$ after stimulation were examined by northern blotting. Densitometric analysis of the $p 21 / G A P D H$ ratio (lower). Values are mean \pm s.d. fold increases relative to untreated cells at time $0(n=7)$. ${ }^{\star} P<0.05$. 
then stained the cells with antibodies against MyHC, myogenin, and creatine kinase (CK), and measured the fusion indices (Figure 2a-c). Adding Ki26894 to the culture media enhanced myoblast fusion and myotube formation. On the other hand, myotube formation was impaired in $\mathrm{C} 2 \mathrm{C} 12$ myoblasts expressing myostatin, activin A, or TGF- $\beta 1$, compared with controls harboring an empty vector (Figure $2 \mathrm{~d}$ and e). Notably, Ki26894 reversed the impaired myotube formation induced by these TGF- $\beta$ family members. Immunoblotting analyses showed that Ki26894 restored the reduced protein expression of $\mathrm{MyHC}$ in $\mathrm{C} 2 \mathrm{C} 12$ myoblasts. These findings indicate that $\mathrm{T} \beta \mathrm{RI}$ kinase inhibitors enhance myoblast differentiation in vitro by suppressing the activity of several members of the anti-myogenic TGF- $\beta$ family members, including activin, or TGF- $\beta 1$, as well as myostatin.

\section{Ki26894 Reverses Reduced Myotube Formation by Forced Expression of Pro104Leu Mutant Caveolin 3}

We previously showed that caveolin 3 binds and suppresses ALK4/5 in COS7 monkey kidney cells by forced expression of these molecules using plasmid vectors. ${ }^{5}$ Moreover, other groups have reported that expression of a CAV3 antisense RNA, or a Pro104Leu dominant-negative mutant CAV3 cDNA suppressed the differentiation of $\mathrm{C} 2 \mathrm{C} 12$ myoblasts into myotubes under low-serum conditions. ${ }^{28,29}$ We thus expressed the Pro104Leu dominant-negative mutant CAV3 cDNA in $\mathrm{C} 2 \mathrm{C} 12$ cells using the above retroviral system, to explore the molecular significance of caveolin 3 and TGF- $\beta$ signals in myoblast differentiation. Similarly to the results of the TGF- $\beta$ expression, myotube formation was impaired in C2C12 myoblasts overexpressing Pro104Leu mutant caveolin 3, compared with controls (Figure 3a-c). Importantly, Ki26894 reversed the impaired myotube formation induced by the mutant caveolin 3 . T $\beta$ RI kinase inhibitors thus could reverse myotube formation by suppressing the enhanced intracellular TGF- $\beta$ signals resulting from a dominant-negative caveolin 3 mutation.

\section{Administration of an Oral T/RRI Kinase Inhibitor Enhances Myogenesis In Vivo in Wild-Type Mice}

Before starting systemic administration of Ki26894, we determined its bioavailability against myostatin activity using an ex-vivo bioassay system. Ki26894 was orally administered in the food to 10-week-old wild-type mice as previously described. ${ }^{18}$ Sera from 12-week-old wild-type mice fed with or without Ki26894 for 2 weeks were added to the culture media of HEK293 cells transfected with a luciferase reporter gene $(n=10$; Supplementary Figure 1$)$. Recombinant myostatin-induced luciferase activity was decreased to $19 \%$ by adding sera from Ki26894-fed mice to the culture media to a final concentration of $25 \%$. Thus, the sera in physiological conditions (50\% in blood) should completely suppress myostatin activity. Therefore, we administered Ki26894 orally to the mice at a concentration of $0.08 \%$ in their food.
Ki26894 was orally administered in powdered food to wild-type mice starting at 6 weeks of age. The body weight of the mice fed with or without Ki26894 was monitored until 16 weeks, when the mice were killed for further analysis. Body weight, peak grip strength force, muscle weight, and single myofiber area (SMA) were larger in mice fed with Ki26894 compared with those not fed with Ki26894, suggesting enhanced myogenesis in vivo (Supplementary Figure 2).

\section{Oral Administration of Ki26894 Rescues Muscle Atrophy in Caveolin 3-Deficient Mice}

We next administered Ki26894 to an atrophic caveolin 3-deficient muscular dystrophy model mouse $\left(\mathrm{CAV} 3^{\mathrm{P} 104 \mathrm{~L}}\right)$, because we previously demonstrated that elevated intramuscular TGF- $\beta$ signals led to muscle atrophy in these mice. ${ }^{5}$ The mice fed with Ki26894 from 9-10 to 16 weeks of age were significantly heavier than those that did not receive Ki26894 $(n=20$; Figure $4 \mathrm{a})$. We did not detect any adverse effects in the mice fed with Ki26894 at any time point until 16 weeks, and no significant pathological abnormalities were found at the end of the experiments, including in the ovary where suppression of activin was reported to cause a reproductive defect $^{30}$ (Supplementary Figure 6). The observation of skinned hind-limb muscles showed that Ki26894 ameliorated muscle atrophy compared with the muscles of untreated mice (Figure 4b). Ki26894 also increased muscle weight in $\mathrm{CAV}^{\mathrm{P} 104 \mathrm{~L}}$ mice (Figure 4c). At 16 weeks of age, H\&E-stained sections of quadriceps femoris muscles from both $\mathrm{CAV} 3^{\mathrm{P} 104 \mathrm{~L}}$ and wildtype mice were examined. As we reported previously, ${ }^{5,11}$ $\mathrm{CAV}^{\mathrm{P} 104 \mathrm{~L}}$ mouse muscle (Figure $4 \mathrm{~d}$, upper) showed marked reduction of myofiber size, compared with wild-type mouse muscle (Figure 4d, lower). Conversely, Ki26894 treatment appeared to alleviate the reduced myofiber size in the $\mathrm{CAV} 3^{\mathrm{P} 104 \mathrm{~L}}$ mice. Morphometric analyses showed that the SMA in the muscles was significantly greater in $\mathrm{CAV} 3^{\mathrm{P} 104 \mathrm{~L}}$ mice treated with Ki26894 than in untreated $\mathrm{CAV} 3^{\mathrm{P} 104 \mathrm{~L}}$ mice (males, $929.7 \pm 320.7$ vs $559.4 \pm 219.4 \mu \mathrm{m}^{2}$; females, $768.3 \pm 335.1$ vs $538.3 \pm 208.1 \mu \mathrm{m}^{2}$; both $P<0.05$; Figure $4 \mathrm{e}$ ). Consistently, the SMA in Ki-treated wild-type mice was also significantly increased compared with that in untreated wild-type mice (males, $3779.1 \pm 762.9$ vs $2937.7 \pm 607.7 \mu \mathrm{m}^{2}$; females, 3389.8 \pm 756.5 vs $2685.4 \pm 746.5 \mu \mathrm{m}^{2}$; both $P<0.05$; Supplementary Figure 2). Thus, long-term administration of Ki26894 induces postnatal myofiber hypertrophy as shown by the increase in mean SMA in $\mathrm{CAV}^{\mathrm{P} 104 \mathrm{~L}}$ mice (males, $\times 1.48$; females, $\times 1.42$ ) and wild-type mice (males, $\times 1.28$; females, $\times 1.26$ ) .

We further examined the effects of Ki26894 on muscle histology other than myofiber size, including the number of EBD-positive necrotic myofibers (Supplementary Figure 3), infiltration of CD11b-positive inflammatory cells (Supplementary Figure 4a) and Masson's trichrome-positive fibrous tissue replacement (Supplementary Figure 4b), and the number of centrally nucleated regenerative myofibers (Supplementary Figure 5). These changes were far less common in $\mathrm{CAV}^{\mathrm{P} 104 \mathrm{~L}}$ mice than in dystrophin-deficient 
a

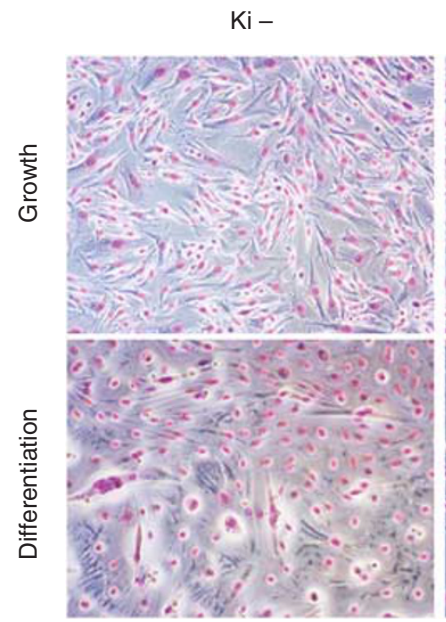

$\mathrm{Ki}+$

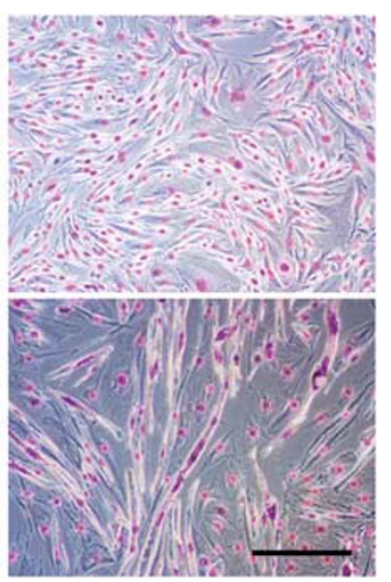

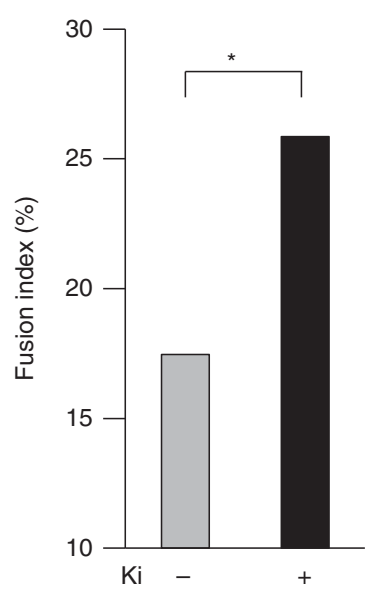

MyHC b

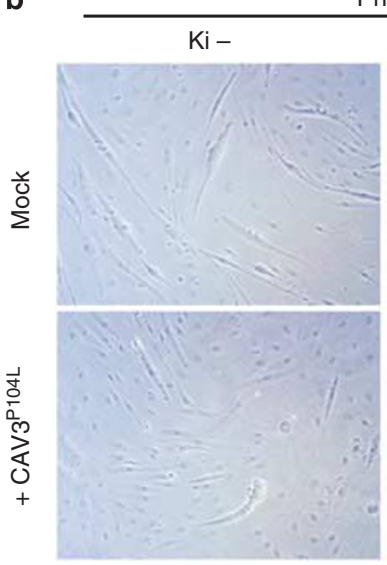

Phase

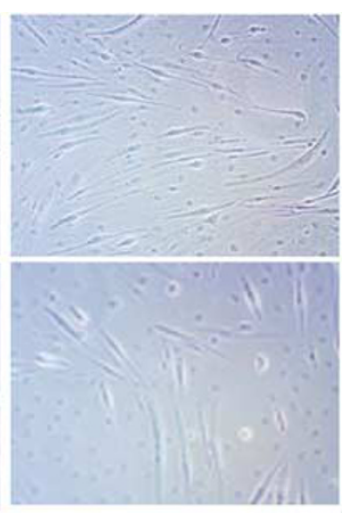

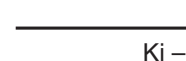
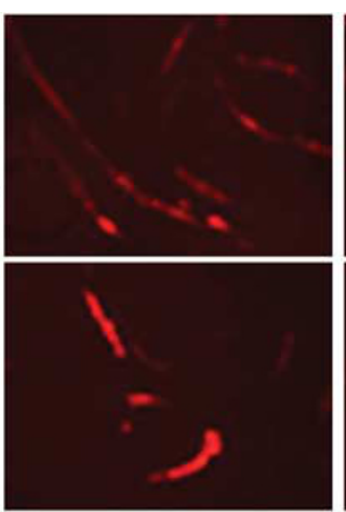
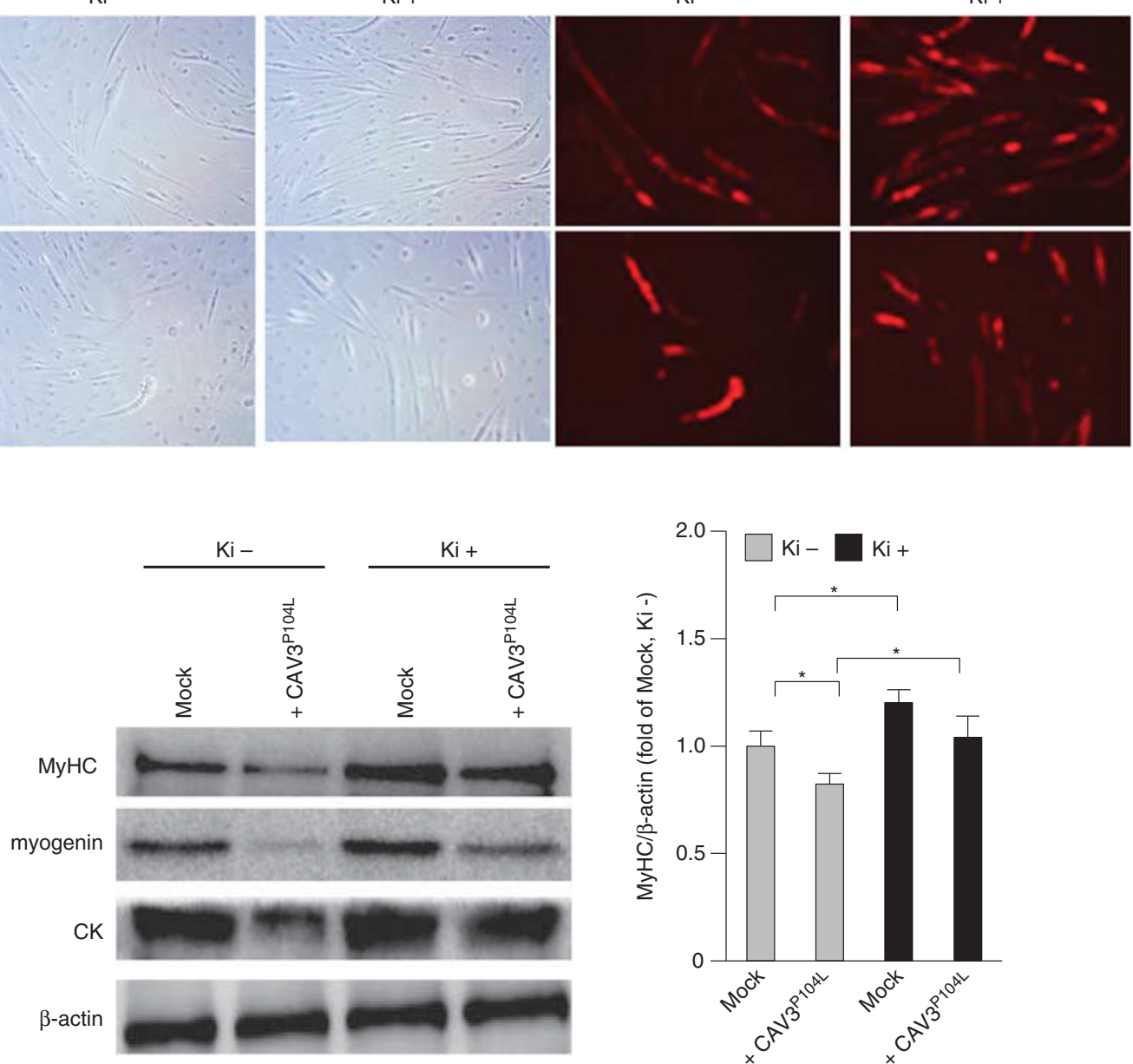

Figure 3 The T $\beta$ RI kinase inhibitor Ki26894 (Ki) restored the impaired in-vitro myogenesis caused by forced expression of Pro104Leu dominant-negative mutant caveolin 3 (CAV3 ${ }^{\mathrm{P} 104 \mathrm{~L}}$ ). (a) Giemsa and Wright-stained images of $\mathrm{C} 2 \mathrm{C} 12$ cells expressing Pro104Leu mutant caveolin 3 in growth medium or differentiation medium without (-) or with (+) Ki26894 (left). Fusion indices of these cells following the addition of $10 \mathrm{nM}$ Ki26894 were calculated in triplicate as the percent of the total nuclei in myotubes $/ \mathrm{mm}^{2}$ (right). Values are means $\pm \mathrm{s} . \mathrm{d}$. $(n=5)$. ${ }^{\star} P<0.05$. (b) C2C12 myoblasts expressing empty vector

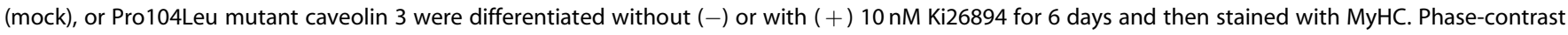
(left) and fluorescent (right) images are shown. Bar, $15 \mu \mathrm{m}$. (c) Protein expression of MyHC, myogenin, and CK in lysates from C2C12 cells expressing empty vector (mock) or Pro104Leu mutant caveolin $3\left(\mathrm{CAV}^{\mathrm{P} 104 \mathrm{~L}}\right)$ at 6 days after differentiation without $(-)$ or with $(+)$ Ki26894 (left). Densitometric analysis of the $\mathrm{MyHC} / \beta$-actin ratio in differentiated $\mathrm{C} 2 \mathrm{C} 12$ cells (right). Values are mean \pm s.d. fold increases compared with untreated $\mathrm{C} 2 \mathrm{C} 12$ lysates expressing empty vector (mock) $(n=5) .{ }^{*} p<0.05$. 

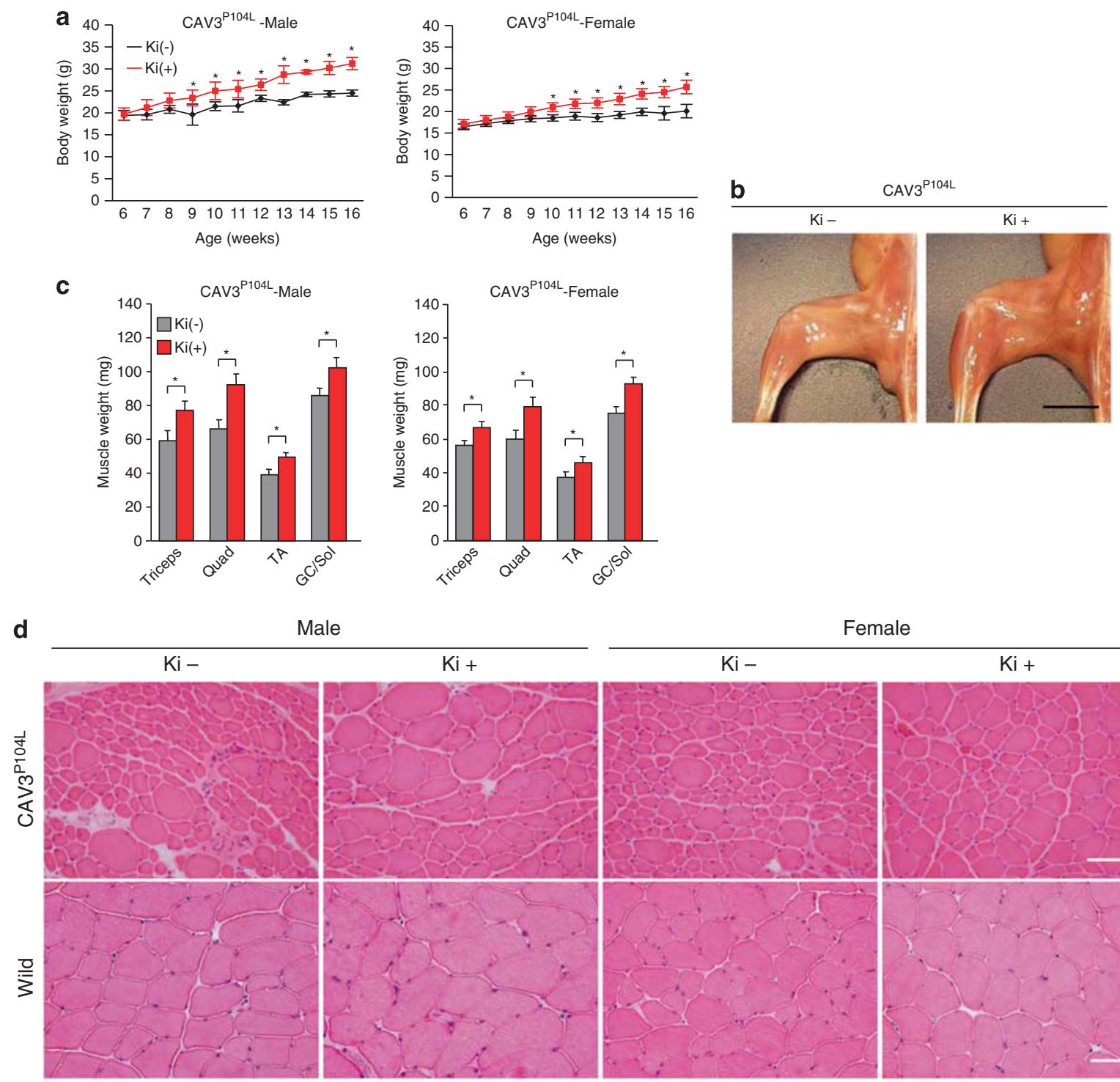

Male $\mathrm{Ki}+$

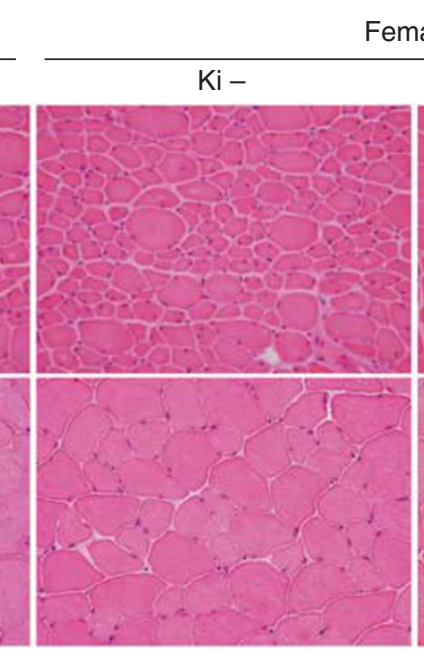

Female
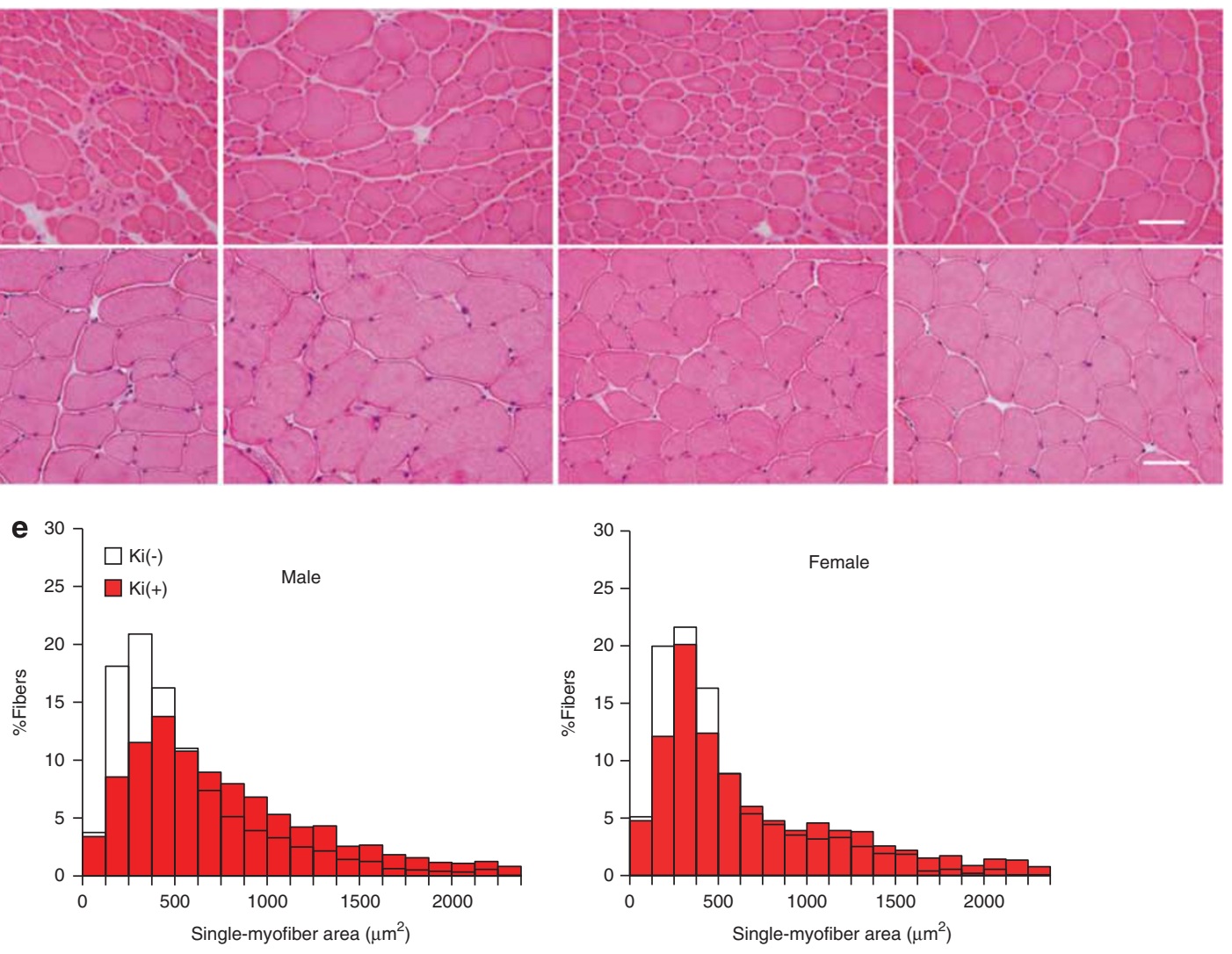

Figure 4 Oral administration of Ki26894 (Ki) ameliorates muscular atrophy and myofiber hypotrophy in caveolin 3-deficient mice. (a) Comparison of body weight at 6 and 16 weeks of age between CAV3 ${ }^{P 104 L}$ mice fed without $(-)$ or with $(+)$ Ki26894. Values are means \pm s.d. $(n=20)$. ${ }^{*} P<0.05$. (b) Appearance of skinned hind limbs from 16-week-old mice fed without (-) or with (+) Ki26894. Scale bar, $5 \mathrm{~mm}$. (c) Comparison of muscle weight in 16-week-old CAV3 ${ }^{\text {P104L }}$ mice fed without $(-)$ or with $(+)$ Ki26894. Triceps, triceps brachii; Quad, quadriceps femoris; GC/Sol, gastrocnemius/soleus. Values are means \pm s.d. $(n=10) .{ }^{*}<0.05$. $(\mathbf{d})$ Histological analysis of the quadriceps femoris in 16-week-old CAV3 ${ }^{\mathrm{P} 104 \mathrm{~L}}$ mice (upper) and wild-type mice (lower) fed without (-) or with (+) Ki26894. Scale bar, $50 \mu \mathrm{m}$. (e) Distribution of SMAs of the quadriceps femoris from 16-week-old CAV3 ${ }^{\mathrm{P} 104 \mathrm{~L}}$ mice ( $n=20 ; 250$ myofibers were assessed in each mouse). 
$m d x$ mice, thereby making it difficult to compare Ki26894treated and Ki26894-untreated muscles. However, we did observe a statistically significant increase in the number of centrally nucleated fibers in Ki26894-treated $\mathrm{CAV}^{\mathrm{P} 104 \mathrm{~L}}$ mouse muscles, suggesting an increase in the amount of muscle regeneration induced by Ki26894.

Peak grip strength force was also greater in Ki26894-treated mice than in untreated mice $(n=20$; Figure $5 \mathrm{a})$. As ex-
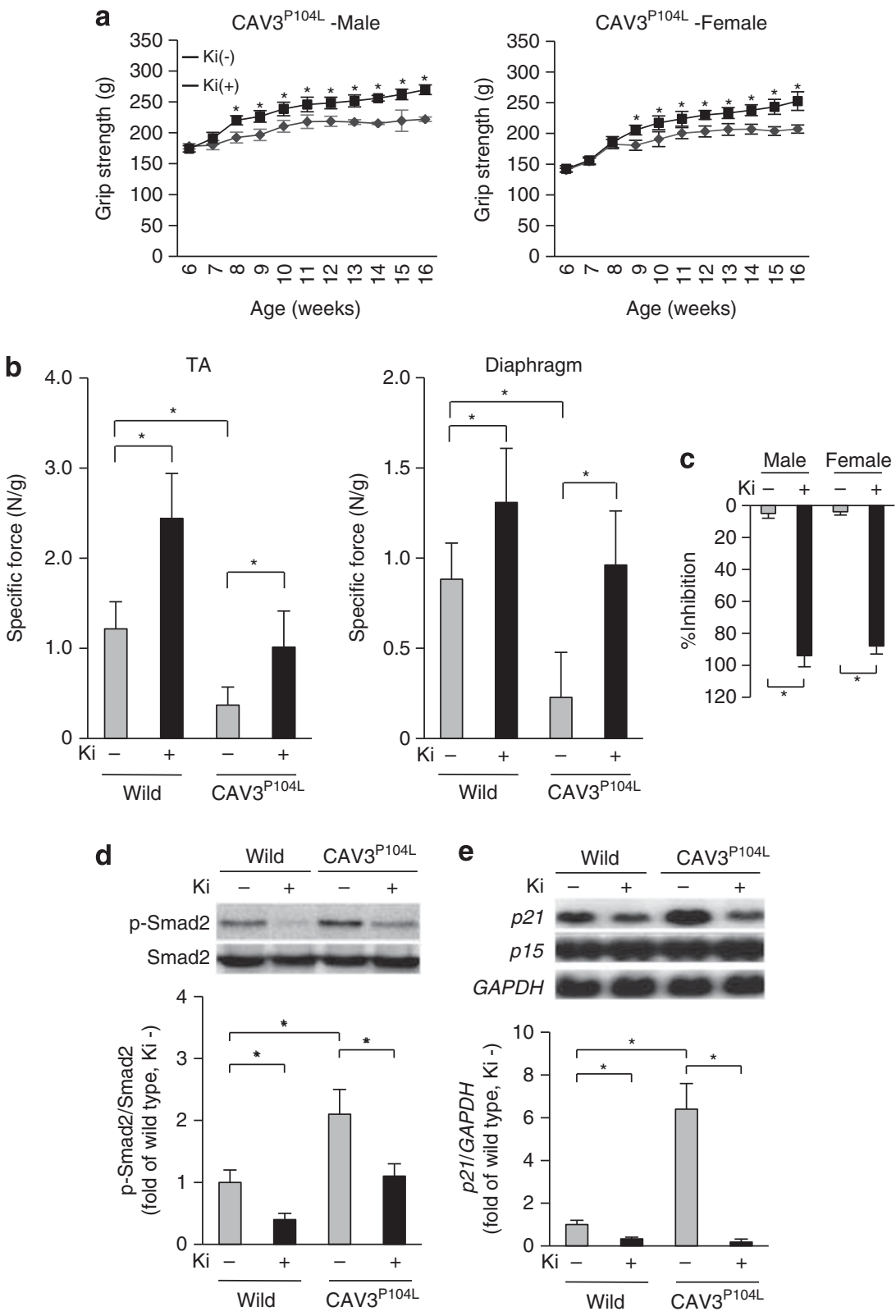

Figure 5 Oral administration of Ki26894 (Ki) rescues muscular weakness in caveolin 3-deficient mice by suppressing intramuscular TGF- $\beta$ signaling. (a) Comparison of peak grip strength $(\mathrm{g})$ at 6 and 16 weeks of age between CAV3 ${ }^{\text {P104L }}$ mice fed without $(-)$ or with $(+)$ Ki26894. Values are means \pm s.d. $(n=20)$. ${ }^{*}<<0.05$. (b) Specific force of the TA or diaphragm from CAV3 ${ }^{P 104 L}$ (left) and wild-type (right) mice at 16 weeks of age fed without $(-)$ or with $(+)$ Ki26894. Maximal tetanic force was assessed at the stimulation frequency of $150 \mathrm{~Hz}$ delivered in $1000 \mathrm{~ms}$ bursts. Values are means $\pm \mathrm{s} . \mathrm{d}$. ( $n=10)$. ${ }^{\star}<<0.05$. (c) Inhibition rate (\%) of ex-vivo myostatin activity by Ki26894. Sera from 12-week-old CAV3 ${ }^{\text {P104L }}$ mice fed without $(-)$ or with $(+)$ Ki26894 were diluted fourfold (to $25 \%$ ) and added to the culture media of HEK293 cells co-transfected with pGL3-(CAGA) 12 -luciferase and pCMV- $\beta$-Gal (internal control), followed by stimulation with $10 \mathrm{ng} / \mathrm{ml}$ myostatin. Luciferase activities were measured and normalized to $\beta$-Gal activity. Recombinant myostatin-induced luciferase activity was decreased by over $80 \%$ by adding the four-fold-diluted sera from mice of both sexes fed with Ki26894. Values are means \pm s.d. $(n=10)$. ${ }^{\star} P<0.05$. (d) Immunoblot analysis of total Smad2 and $p$-Smad2 in crude muscle homogenates from wild-type and CAV3 ${ }^{P 104 L}$ mice fed without ( - ) or with $(+)$ Ki26894 (upper). p-Smad2/Smad2 ratios determined by densitometric analysis (lower). Values are mean \pm s.d. fold increases with respect to wild-type mice $(n=7)$. ${ }^{*} P<0.05$. (e) Northern blot analysis of $p 21$ and $p 15$ in muscles from CAV3 ${ }^{\text {P104L }}$ mice fed without ( - ) or with $(+)$ Ki26894 (upper). Densitometric analysis of the $p 21 / G A P D H$ ratio (lower). Values are mean \pm s.d. fold increases compared with untreated wild-type mice $(n=7)$. ${ }^{\star} P<0.05$. 
pected, the specific force of the TA or diaphragm muscles was significantly lower in $\mathrm{CAV} 3^{\mathrm{P} 104 \mathrm{~L}}$ mice than in wild-type mice $(n=7$; Figure 5b). Oral Ki26894 increased muscle-specific force both in $\mathrm{CAV}^{\mathrm{P} 104 \mathrm{~L}}$ mice and in wild-type mice. We also found that serum myostatin activity was significantly reduced in Ki26894-treated CAV3 ${ }^{\mathrm{P} 104 \mathrm{~L}}$ mice compared with that in untreated mice at 15 weeks of age (Figure $5 \mathrm{c}$ ).

\section{Ki26894 Decreases the Intramuscular TGF- $\beta$ Signal and Increases the Number of Satellite Cells In Vivo}

To investigate the intramuscular TGF- $\beta$ signal, we examined the levels of p-Smad2, its intracellular effector, in crude muscle homogenates ( $n=7$; Figure $5 \mathrm{~d}$ ). The amounts of total Smad2 protein were comparable in wild-type and $\mathrm{CAV} 3^{\mathrm{P} 104 \mathrm{~L}}$ mice, with or without $\mathrm{Ki}$ treatment, whereas the level of p-Smad2 was significant increased in CAV3 ${ }^{\mathrm{P} 104 \mathrm{~L}}$ mice compared with wild-type mice. Ki treatment significantly reduced p-Smad2 levels in both lines of mice. We further investigated the expression of p21 and p15 in the skeletal muscle of $\mathrm{CAV}^{\mathrm{P} 104 \mathrm{~L}}$ mice to determine the effects of Ki26894 on intramuscular signaling ( $n=7$; Figure $5 \mathrm{e}$ ). The mRNA expression of $p 21$ was increased in $\mathrm{CAV} 3^{\mathrm{P} 104 \mathrm{~L}}$ mice compared with wild-type mice, suggesting enhanced intramuscular TGF- $\beta$ signaling caused by loss of caveolin 3. Importantly, oral Ki26894 administration decreased $p 21$ expression in both wild-type and $\mathrm{CAV} 3^{\mathrm{P} 104 \mathrm{~L}}$ mice. In contrast, $p 15$ expression was not affected by oral administration of Ki26894. These results are consistent with our in-vitro findings that $\mathrm{T} \beta \mathrm{RI}$ kinase inhibitors suppress intracellular signaling pathways activated by members of the anti-myogenic TGF- $\beta$ family.

Muscle precursor satellite cells reside beneath the basal lamina of the myofibers, where they have important roles in postnatal muscle growth as resident stem cells in adult skeletal muscle. ${ }^{31}$ We evaluated satellite cells in the quadriceps femoris muscles of CAV3 ${ }^{\mathrm{P} 104 \mathrm{~L}}$ mice compared with wild-type mice by immunostaining for the marker protein M-cadherin. At both time points $(6,10$, or 24 weeks of age), the number of M-cadherin-positive satellite cells in muscles from the caveolin 3-deficient transgenic mice was reduced compared with that in the wild-type mice, accompanied by a reduction in myofiber size (Figure 6a). Because the number of satellite cells in skeletal muscle is known to reduce with age, ${ }^{31}$ we counted the number of satellite cells per 100 myofibers or per 100 myonuclei from the quadriceps femoris muscles of mice at three time points $(6,10$, or 24 weeks of age; $n=7$, Figure 6b). Compared with the wild-type mice, the caveolin 3-deficient transgenic mice showed a significant reduction in the number of satellite cells at all time points, not only per 100 myofibers, but also per 100 myonuclei. Thus, satellite cell reduction could contribute to the cellular mechanism leading to muscle atrophy in caveolin 3-deficient mice. Consistently, at 16 weeks of age, we found fewer satellite cells in the quadriceps femoris muscles of $\mathrm{CAV} 3^{\mathrm{P} 104 \mathrm{~L}}$ mice than in wildtype mice ( $n=7$; Figure $6 \mathrm{c}$ and d, left). Conversely, Ki26894 increased the numbers of satellite cells in both caveolin 3-deficient mice and wild-type mice $(n=7$; Figure $6 \mathrm{c}$ and d, right). These findings were confirmed using another M-cadherin antibody ( $n=7$; Supplementary Figure 7$)$. T $\beta$ RI kinase inhibitors thus increased resident stem cells in both caveolin 3-deficient and normal adult muscle.

Caveolin 1, another isoform of caveolins, was reported to be expressed in M-cadherin-positive satellite cells. ${ }^{32}$ To confirm this finding, we stained single myofibers isolated from the EDL muscles of wild-type mice. Because the above two anti-M-cadherin antibodies used in histochemistry showed weak immunoreactivities on satellite cells attached to isolated single myofibers (data not shown), we used an antibody against Pax7, another marker of satellite cells. An anticaveolin-1 antibody stained the regions surrounding Pax-7positive mononucleated cell attached to a single myofiber from wild-type mice (Supplementary Figure 7b). Double immunostaining for caveolin 1 and caveolin 3 showed caveolin 1-positive cells located outside of the caveolin 3-positive sarcolemma, confirming the report that caveolin 1 is expressed in the cytoplasm and/or the plasma membrane of satellite cells, whereas caveolin 3 is expressed in the sarcolemma $^{32}$ (Supplementary Figures $7 \mathrm{c}$ and 8 ). Using the antibody against caveolin 1, we analyzed satellite cells attached to isolated single myofiber from $\mathrm{CAV}^{\mathrm{P} 104 \mathrm{~L}}$ and wild-type mice fed with or without Ki26894 (Figure 6e). Single myofiber isolated from muscles of $\mathrm{CAV} 3^{\mathrm{P} 104 \mathrm{~L}}$ mice had a reduced number of caveolin 1-positive satellite cells, compared with that of wild-type mice. Ki treatment appeared to alleviate the reduced number of satellite cells and the reduced size of myofiber in CAV3 ${ }^{\mathrm{P} 104 \mathrm{~L}}$ mice. Quantitative analyses revealed that the numbers of satellite cells per 100 myofibers significantly increased following Ki treatment in isolated myofibers from both lines of mice $(n=7)$.

\section{DISCUSSION}

A growing number of molecules have recently been demonstrated to participate in the molecular mechanisms leading to skeletal muscle atrophy. However, no effective pharmacological intervention is currently available to improve muscle atrophy, except oral steroids, which are of limited efficacy. ${ }^{3,4}$ Small-molecular inhibitors targeting membrane receptor tyrosine or serine/threonine kinases have been highlighted, and in part, are clinically available as molecular-targeting agents for cancer therapy. ${ }^{33}$ In the present study, using such an inhibitor of T $\beta$ RI kinase as an optimal probe, we found that the decrease in muscle precursor satellite cells and impairment of myoblast differentiation that accompanied activation of the TGF- $\beta$ signaling pathway led to muscular atrophy in a caveolin 3-deficient mouse model. By suppression of multiple anti-myogenic TGF- $\beta$ signals, oral small-molecule T $\beta$ RI inhibitors could become an alternative, rationally designed, molecular-targeting agent for treating muscular atrophy in various clinical settings besides caveolin 3 deficiency. 
a
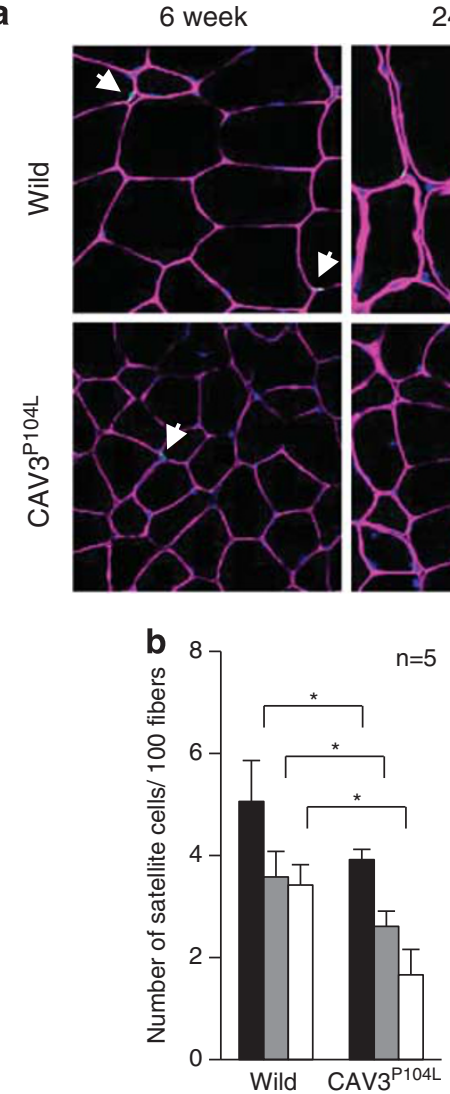

24 week
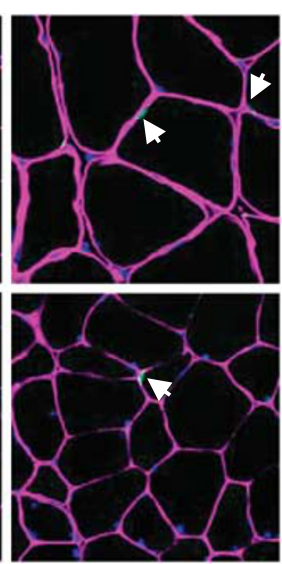

c
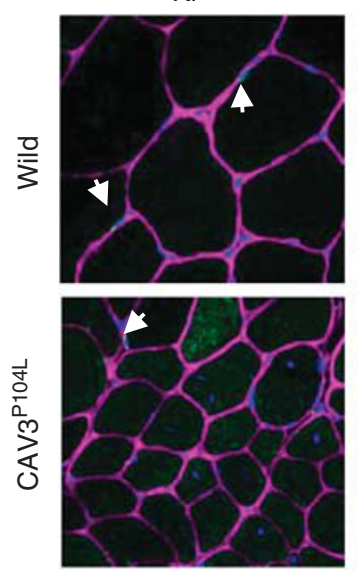

$\mathrm{Ki}+$
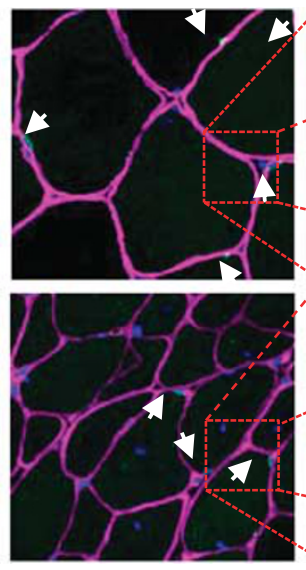
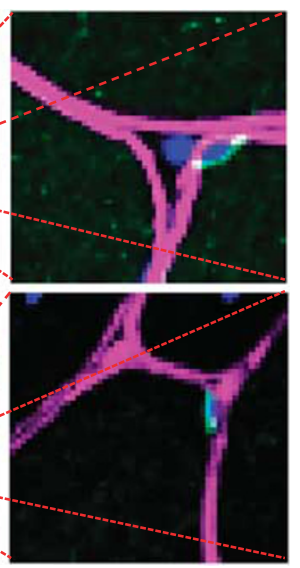
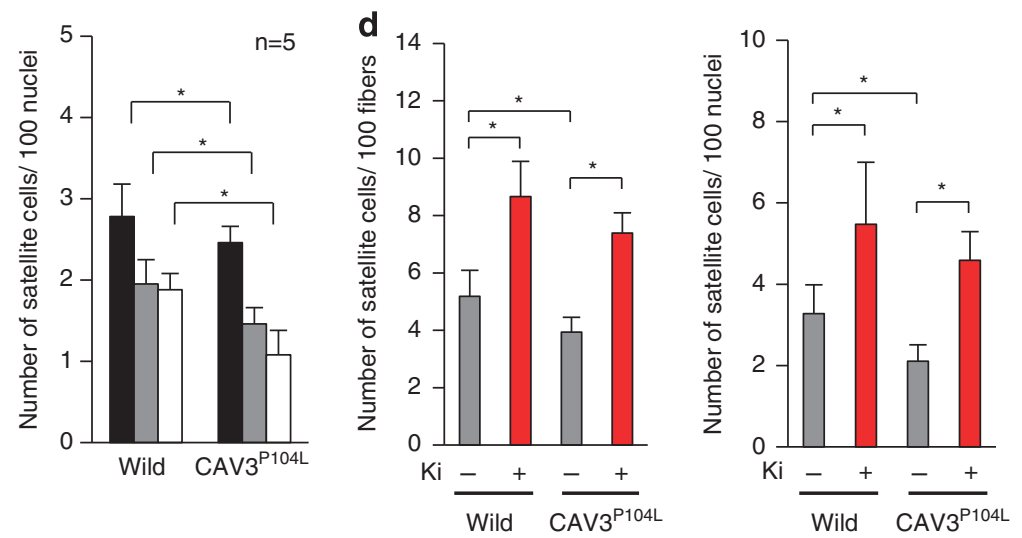

e

Wild
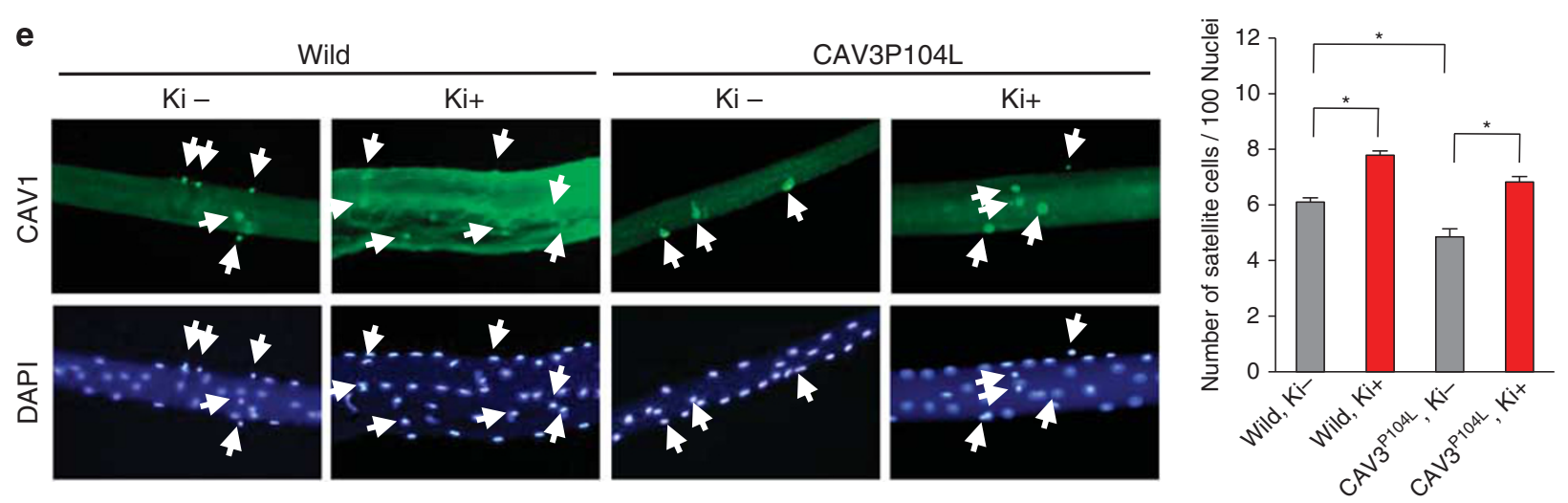

Figure $6 \mathrm{Ki} 26894$ (Ki) reverses the reduced number of satellite cells in caveolin 3-deficient LGMD1C model mice. (a) Immunohistochemical analysis of satellite cells of the quadriceps femoris from 6- or 16-week-old wild-type (Wild) or CAV3 ${ }^{\text {P104L }}$ mice using an antibody raised against the carboxyl-terminal region of mouse M-cadherin. At both ages, the number of $\mathrm{M}$-cadherin-positive satellite cells in muscles from caveolin 3-deficient transgenic mice was decreased compared with that in wild-type mice. M-cadherin, laminin $\alpha 2$, and the nuclei are stained green, magenta, and blue, respectively. White arrow, M-cadherin-positive satellite cells residing beneath the basal lamina. Scale bar, $50 \mu \mathrm{m}$. (b) The number of satellite cells/100 myofibers (left) or 100 myonuclei (right) in quadriceps femoris muscles from wild-type or CAV3 ${ }^{\text {P104L }}$ mice was counted at 6 (black), 10 (gray), or 16 (white) weeks of age ( $n=7 ; 1000$ myofibers or myonuclei were assessed for each mouse). Values are means \pm s.d., $n=7$. ${ }^{*} P<0.05$. (c) Satellite cells of quadriceps femoris muscles from 16 -week-old wildtype or CAV3 ${ }^{\mathrm{P} 104 \mathrm{~L}}$ mice fed with $(+)$ or without $(-)$ Ki26894. Oral Ki26894 reversed the reduced number of satellite cells in CAV3 ${ }^{\mathrm{P} 104 \mathrm{~L}}$ mice and increased the number of satellite cells in CAV3 ${ }^{\mathrm{P} 104 \mathrm{~L}}$ mice. Scale bar, $50 \mu \mathrm{m}$. The enlarged images of the boxed regions included satellite cells are shown on the right side of the original picture. (d) The number of satellite cells/100 myofibers (left) or 100 myonuclei (right) in quadriceps femoris muscles from wild-type or $\mathrm{CAV}^{\mathrm{P} 104 \mathrm{~L}}$ mice, fed without (gray) or with (red) Ki26894. ${ }^{\star} P<0.05$. (e) Fluorescence images of caveolin 1 , a satellite cell marker protein (green), and nuclei (blue), in a single myofibers isolated from the EDL muscles of wild-type and CAV3 ${ }^{\mathrm{P} 104 \mathrm{~L}}$ mice aged 16 weeks. The white arrow indicates caveolin 1-positive satellite cells attached to the myofiber (left). Quantification of the number of caveolin 1-positive satellite cells attached to a single myofiber (right). Number of satellite cells per 100 myonuclei in a single myofiber from the EDL muscles of 16-week-old mice. Ki treatment significantly increased the number of satellite cells in wild-type mice and alleviated the reduction in the number of satellite cells in CAV $3^{\mathrm{P} 104 \mathrm{~L}}$ mouse myofibers. Data are mean values $\pm \mathrm{s}$.d. $(n=5$; 10 myofibers were assessed for each mice). ${ }^{*} P<0.05$. 
We revealed that the three $\mathrm{T} \beta \mathrm{R} I$ kinase inhibitors tested suppressed the intracellular signals of TGF- $\beta 1$, activin, and myostatin in A204 human rhabdomyosarcoma cells and HEK293 embryonic kidney cells. However, the inhibition profile of one inhibitor, Ki26894, against the TGF- $\beta 1$ and activin signal, differed between A204 human rhabdomyosarcoma cells and HEK293 embryonic kidney cells. Previous studies have shown that individual $\mathrm{T} \beta \mathrm{RI}$ kinase inhibitors have different half-maximal inhibitory concentration values or different dissociation constant values for each receptor. ${ }^{12,19,20}$ Such an inhibition profile may be due to pharmacological differences between each compound, as well as differences in receptor expression in the assayed cells. Similarly to the results of A204 cells, Ki26894 broadly suppressed the upregulation of p21 induced by myostatin, activin, and TGF- $\beta 1$ in $\mathrm{HaCaT}$ cells. These results suggest that $\mathrm{T} \beta \mathrm{RI}$ kinase inhibitors can suppress multiple intracellular TGF- $\beta$ signaling pathways at their membrane receptor levels.

We also demonstrated that Ki26894 enhanced C2C12 myoblast fusion and differentiation into myotubes under low-serum conditions. Previous studies showed that myostatin, activin, or TGF- $\beta 1$ impaired myogenic differentiation in cultured myogenic cells from several species. ${ }^{27,34-36}$ Using an efficient retroviral gene expression system, we confirmed that these three molecules independently suppressed mouse $\mathrm{C} 2 \mathrm{C} 12$ myoblast differentiation. Conversely, the addition of Ki26894 almost completely restored the myotube formation that was impaired by the TGF- $\beta$ family members. Taken together, Ki26894 enhances myoblast differentiation into myotubes in vitro by suppressing the multiple intracellular anti-myogenic TGF- $\beta$ signaling pathways. Ki26894 similarly restored the impaired $\mathrm{C} 2 \mathrm{C} 12$ myoblast differentiation induced by forced expression of the P104L mutant caveolin 3.

Consistent with our in-vitro results, oral administration of Ki26894 increased myofiber size and muscle mass in wildtype mice, suggesting enhanced in-vivo myogenesis in normal adult muscles. As expected, Ki26894 prevented muscle atrophy in TGF- $\beta$-activated muscles in a P104L mutant caveolin 3 model mouse. Besides myostatin, other members of the TGF- $\beta$ family have recently been demonstrated to suppress myogenesis in vivo. ${ }^{37-40}$ Transgenic overexpression of follistatin, an inhibitory binding protein of myostatin and activin, enhanced muscularity in mice lacking myostatin. ${ }^{37}$ Additionally, conditional deletion of an activin gene increased muscle mass, indicating that activin has a role in suppressing myogenesis in vivo. ${ }^{38}$ Moreover, activated intramuscular TGF- $\beta$ signaling was observed in atrophic muscles from dystrophin-deficient muscular dystrophy patients with impaired muscle regeneration and increased fibrosis. ${ }^{39,40}$ Therefore, Ki26894 may block the intramuscular signaling of activin and TGF- $\beta 1$, as well as myostatin. Consistent with these in-vitro observations, Ki26894 reduced the increase in the levels of p-Smad2, a TGF- $\beta$ effector, and reduced upre- gulation of $p 21$, a target gene of TGF- $\beta$ family members in treated muscles.

Satellite cells are the resident stem cells of adult skeletal muscles. The caveolin 3-deficient muscles in these mice showed a reduced number of satellite cells in both skeletal muscle sections and isolated single myofibers, compared with wild-type mice. Conversely, the oral T $\beta$ RI kinase inhibitor restored the reduced number of satellite cells in caveolin 3deficient atrophic myofibers, in which p21 expression was upregulated. This inhibitor also increased the number of satellite cells in wild-type mouse muscles. TGF- $\beta 1$-induced p21 upregulation in satellite cells contributed to myofiber hypotrophy in sarcopenia and impaired muscle regeneration in aged mouse muscles. ${ }^{41}$ Thus, T $\beta$ RI kinase inhibitors may increase satellite cells both in atrophic and in normal myofiber by suppressing the TGF- $\beta-$ p 21 axis. However, the effects of myostatin on satellite cells are controversial, because one study revealed an increased number of satellite cells in mice lacking myostatin, ${ }^{42}$ whereas another study showed no increase in the number of satellite cells in the same mice. ${ }^{43}$ Thus, T $\beta$ RI kinase inhibitors may increase the number of satellite cells by suppressing members of the TGF- $\beta$ family other than myostatin, which show similar but not identical intramuscular signaling pathways involving p21. Taken together with the in-vitro results, these observations indicate that oral T $\beta$ RI inhibitors enhance myogenesis via satellite cells and myoblasts through the caveolin-TGF- $\beta-$ p21 axis.

In a phase I/II clinical trial, the anti-myostatin neutralizing antibody MYO-029 was reported to dose dependently increase myofiber diameter, but did not improve muscular weakness in patients with muscular dystrophy. ${ }^{44}$ Additionally, myostatin-null mice did not exhibit an increase in muscle strength despite an increase in muscle mass. ${ }^{45}$ However, administration of Ki26894 enhanced muscle performance in wild-type mice and ameliorated muscular weakness in caveolin 3-deficient mice, as revealed by an increase in grip strength and muscle-specific forces. Thus, pharmacological intervention strategies based on T $\beta$ RI kinase inhibitors that can suppress the broad TGF- $\beta$ signaling pathways would be expected to prevent the progression of muscle weakness better than strategies employing other inhibitors that suppress myostatin signaling alone. To evaluate the effect on muscle performance, T $\beta$ RI kinase inhibitors should be tested in other, larger animal models of muscular atrophy. ${ }^{46}$

Long-term administration of Ki26894 had no adverse effects in caveolin 3-deficient mice based on pathological examination of the major organs. Additionally, there were no adverse effects of T $\beta$ RI kinase inhibitors in animal models of cancers, lung fibrosis, or renal fibrosis. ${ }^{15-18,47,48}$ However, it is necessary to define the optimal, but non-toxic dosage of these drugs for the treatment of individual patients with muscular atrophy. In this respect, our ex-vivo myostatin activity assay is a convenient real-time biomonitoring system to determine how myostatin signaling is affected by the administration of 
these drugs in individual patients. Both an increase in the number of satellite cells and the enhancement of myoblast differentiation provide a new therapeutic avenue for this type of inhibitor as an off-label drug for the treatment of muscle atrophy in various clinical settings, including muscular dystrophies, sarcopenia, and possibly cancer cachexia.

In agreement with our first report ${ }^{5}$ two other groups have recently shown that caveolin 3 deficiency causes muscle atrophy through intramuscular TGF- $\beta$ activation..$^{29,49} \mathrm{Ca}$ veolin 3-deficient myoblasts formed thin myotubes upon activation of the TGF- $\beta$ effector, Smad2. ${ }^{29}$ Activated Smad2 was also observed in skeletal muscle from patients with muscular dystrophy with generalized lipodystrophy caused by deficiency of cavin, an assembly molecule for caveolin $3 .{ }^{49}$ To confirm the novel concept of the caveolin 3-TGF- $\beta-$ p21 axis in the pathobiology of muscle atrophy, further characterization of both satellite cells and myoblasts will be required in skeletal muscle samples from patients with LGMD1C and cavin 1 deficiency.

Supplementary Information accompanies the paper on the Laboratory Investigation website (http://www.laboratoryinvestigation.org)

\section{ACKNOWLEDGEMENTS}

We thank Drs MR Kano and K Miyazono (Department of Molecular Pathology, The University of Tokyo), T Imamura (Department of Biochemistry, The Cancer Institute of the Japanese Foundation for Cancer Research), and A Uezumi (Division for Therapies against Intractable Diseases, Institute for Comprehensive Medical Science, Fujita Health University) for valuable advice, and T Kenmotsu and N Naoe (Department of Neurology, Kawasaki Medical School) for providing technical assistance. This work was supported by research grants for Intramural Neurological and Psychiatric Disorders from the National Center of Neurology and Psychiatry (20B-13, 23-5); grants for Comprehensive Research on Disability Health and Welfare from the Ministry of Health, Labour, and Welfare of Japan (H20-018); a Grant-in-Aid for Scientific Research from the Japan Society for the Promotion of Science (C-20591013, C-21591101 and C-23591261); and research project grants from Kawasaki Medical School (22-A24, 22-T1, 23-B60, 23-T1).

\section{DISCLOSURE/CONFLICT OF INTEREST}

The authors declare no conflict of interest.

1. Tsuchida K, Nakatani M, Uezumi A, et al. Signal transduction pathway through activin receptors as a therapeutic target of musculoskeletal diseases and cancer. Endocr J 2008;55:11-21.

2. Tisdale MJ. Reversing cachexia. Cell 2010;142:511-512.

3. Glass DJ. Signaling pathways perturbing muscle mass. Curr Opin Clin Nutr Metab Care 2010;3:225-229.

4. Guglieri M, Bushby K. Molecular treatments in Duchenne muscular dystrophy. Curr Opin Pharmacol 2010;10:331-337.

5. Ohsawa $Y$, Hagiwara $H$, Nakatani $M$, et al. Muscular atrophy of caveolin3-deficient mice is rescued by myostatin inhibition. J Clin Invest 2006;116:2924-2934.

6. Ohsawa $Y$, Okada T, Kuga A, et al. Caveolin-3 regulates myostatin signaling. Mini-review. Acta Myol 2008;27:19-24.

7. Mcpherron AC, Lawler AM, Lee SJ. Regulation of skeletal muscle mass in mice by a new TGF-beta superfamily member. Nature 1997;387: 83-90.

8. Zimmers TA, Davies MV, Koniaris LG, et al. Induction of cachexia in mice by systemically administered myostatin. Science 2002;296: 1486-1488.
9. Gazzerro E, Sotgia F, Bruno C, et al. Caveolinopathies: from the biology of caveolin-3 to human diseases. Eur J Hum Genet 2010;18:137-145.

10. Minetti $C$, Sotgia $F$, Bruno $C$, et al. Mutations in the caveolin-3 gene cause autosomal dominant limb-girdle muscular dystrophy. Nat Genet 1998; 18:365-368.

11. Sunada $Y$, Ohi $H$, Hase $A$, et al. Transgenic mice expressing mutant caveolin-3 show severe myopathy associated with increased nNOS activity. Hum Mol Genet 2001;10:173-178.

12. Yingling JM, Blanchard KL, Sawyer JS. Development of TGF-beta signalling inhibitors for cancer therapy. Nat Rev Drug Discov 2004;3: 1011-1022.

13. Derynck R, Akhurst RJ, Balmain A. TGF-beta signaling in tumor suppression and cancer progression. Nat Genet 2001;29:117-129.

14. Massagué J. TGF-beta signal transduction. Annu Rev Biochem 1998; 67:753-791.

15. Uhl M, Aulwurm S, Wischhusen J, et al. SD-208, a novel transforming growth factor beta receptor I kinase inhibitor, inhibits growth and invasiveness and enhances immunogenicity of murine and human glioma cells in vitro and in vivo. Cancer Res 2004;64:7954-7961.

16. Bandyopadhyay A, Agyin JK, Wang L, et al. Inhibition of pulmonary and skeletal metastasis by a transforming growth factor-beta type I receptor kinase inhibitor. Cancer Res 2006;66:6714-6721.

17. Ehata S, Hanyu A, Fujime $M$, et al. Ki26894, a novel transforming growth factor-beta type I receptor kinase inhibitor, inhibits in vitro invasion and in vivo bone metastasis of a human breast cancer cell line. Cancer Sci 2007;98:127-133.

18. Kano MR, Bae $Y$, Iwata $C$, et al. Improvement of cancer-targeting therapy, using nanocarriers for intractable solid tumors by inhibition of TGF-beta signaling. Proc Natl Acad Sci USA 2007;104:3460-3465.

19. Callahan JF, Burgess JL, Fornwald JA, et al. Identification of novel inhibitors of the transforming growth factor beta1 (TGF-beta1) type 1 receptor (ALK5). J Med Chem 2002;45:999-1001.

20. Sawyer JS, Anderson BD, Beight DW, et al. Synthesis and activity of new aryl- and heteroaryl-substituted pyrazole inhibitors of the transforming growth factor-beta type I receptor kinase domain. J Med Chem 2003;46:3953-3956.

21. Jonk $\mathrm{L}$, Itoh $\mathrm{S}$, Heldin $\mathrm{CH}$, et al. Identification and functional characterization of a Smad binding elements (SBE) in theJunB promoter that acts as a transforming growth factor-beta, activin, and bone morphogenetic protein-inducible enhancer. J Biol Chem 1998; 273:21145-21152.

22. Kitamura $T$, Koshino $Y$, Shibata $F$, et al. Retrovirus-mediated gene transfer and expression cloning: powerful tools in functional genomics. Exp Hematol 2003;31:1007-1014.

23. Rosenblatt JD, Lunt Al, Parry DJ, et al. Culturing satellite cells from living single muscle fiber explants. In Vitro Cell Dev Biol Anim 1995;31:773-779.

24. Matsuda R, Nishikawa A, Tanaka H. Visualization of dystrophic muscle fibres in mdx mouse by vital staining with Evans blue: evidence of apoptosis in dystrophin-deficient muscle. J Biochem 1995;118: 959-964.

25. Xiao X, Li J, Tsao YP, et al. Full functional rescue of a complete muscle (TA) in dystrophic hamsters by adeno-associated virus vector-directed gene therapy. J Virol 2000;74:1436-1442.

26. Luo Y, Hurwitz J, Massagué J. Cell-cycle inhibition by independent CDK and PCNA binding domains in p21Cip1. Nature 1995;375:159-161.

27. Ríos R, Carneiro I, Arce VM, et al. Myostatin is an inhibitor of myogenic differentiation. Am J Physiol Cell Physiol 2002;282:C993-C999.

28. Galbiati F, Volonte D, Engelman JA, et al. Targeted down-regulation of caveolin-3 is sufficient to inhibit myotube formation in differentiating $\mathrm{C} 2 \mathrm{C} 12$ myoblasts. Transient activation of p38 mitogen-activated protein kinase is required for induction of caveolin-3 expression and subsequent myotube formation. J Biol Chem 1999;274:30315-30321.

29. Stoppani E, Rossi $S$, Meacci E, et al. Point mutated caveolin-3 form (P104L) impairs myoblast differentiation via Akt and p38 signalling reduction, leading to an immature cell signature. Biochim Biophys Acta 2011;1812:468-479.

30. Vassalli A, Matzuk MM, Gardner HA, et al. Activin/inhibin beta B subunit gene disruption leads to defects in eyelid development and female reproduction. Genes Dev 1994;15:414-427.

31. Cerletti $M$, Shadrach $\mathrm{J}$, Jurga $\mathrm{S}$, et al. Regulation and function of skeletal muscle stem cells. Cold Spring Harb Symp Quant Biol 2008; 73:317-322. 
32. Volonte D, Liu Y, Galbiati F. The modulation of caveolin-1 expression controls satellite cell activation during muscle repair. FASEB J 2005; 19:237-239.

33. Fabian MA, Biggs 3rd WH, Treiber DK, et al. A small molecule-kinase interaction map for clinical kinase inhibitors. Nat Biotechnol 2005;23:329-336.

34. Olson EN, Sternberg $\mathrm{E}$, Hu JS, et al. Regulation of myogenic differentiation by type beta transforming growth factor. J Cell Biol 1986;103:1799-1805.

35. Massagué J, Cheifetz S, Endo T, et al. Type beta transforming growth factor is an inhibitor of myogenic differentiation. Proc Natl Acad Sci USA 1986;83:8206-8210.

36. Shiozuka M, Kimura I. Developmental stage-related sensitivity of chick primary myogenic cells to differentiation-inhibiting effect of activin A J Hum Sci 1999;11:56-63.

37. Lee SJ. Quadrupling muscle mass in mice by targeting TGF-beta signaling pathways. PLoS ONE 2007;2:E789.

38. Lee SJ, Lee YS, Zimmers TA, et al. Regulation of muscle mass by follistatin and activins. Mol Endocrinol 2010;24:1998-2008.

39. Bernasconi $\mathrm{P}$, Torchiana $\mathrm{E}$, Confalonieri $\mathrm{P}$, et al. Expression of transforming growth factor-beta 1 in dystrophic patient muscles correlates with fibrosis. Pathogenetic role of a fibrogenic cytokine. J Clin Invest 1995;96:1137-1144.

40. Cohn RD, van Erp C, Habashi JP, et al. Angiotensin II type 1 receptor blockade attenuates TGF-beta-induced failure of muscle regeneration in multiple myopathic states. Nat Med 2007;13:204-210.
41. Carlson $M E$, Hsu M, Conboy IM. Imbalance between pSmad3 and notch induces CDK inhibitors in old muscle stem cells. Nature 2008;454:528-532

42. Mccroskery S, Thomas M, Maxwell L, et al. Myostatin negatively regulates satellite cell activation and self-renewal. J Cell Biol 2003;162: 1135-1147.

43. Amthor $\mathrm{H}$, Otto $\mathrm{A}$, Vulin $\mathrm{A}$, et al. Muscle hypertrophy driven by myostatin blockade does not require stem/precursor-cell activity. Proc Natl Acad Sci USA 2009;106:7479-7484.

44. Wagner KR, Fleckenstein $\mathrm{JL}$, Amato AA, et al. A phase I/II trial of MYO 029 in adult subjects with muscular dystrophy. Ann Neurol 2008;63: 561-571.

45. Amthor $\mathrm{H}$, Macharia $\mathrm{R}$, Navarrete $\mathrm{R}$, et al. Lack of myostatin results in excessive muscle growth but impaired force generation. Proc Nat Acad Sci USA 2007;104:1835-1840.

46. Yokota T, Lu QL, Partridge T, et al. Efficacy of systemic morpholino exonskipping in Duchenne dystrophy dogs. Ann Neurol 2009;65:667-676.

47. Bonniaud $\mathrm{P}$, Margetts $\mathrm{PJ}$, Kolb $\mathrm{M}$, et al. Progressive transforming growth factor beta1-induced lung fibrosis is blocked by an orally active ALK5 kinase inhibitor. Am J Respir Crit Care Med 2005;171:889-898.

48. Moon JA, Kim HT, Cho IS, et al. IN-1130, a novel transforming growth factor-beta type I receptor kinase (ALK5) inhibitor, suppresses renal fibrosis in obstructive nephropathy. Kidney Int 2006;70:1234-1243.

49. Hayashi YK, Matsuda C, Ogawa M, et al. Human PTRF mutations cause secondary deficiency of caveolins resulting in muscular dystrophy with generalized lipodystrophy. J Clin Invest 2009;119:2623-2633. 